INSTITUTO DE PESQUISAS ENERGÉTICAS E NUCLEARES

AUTARQUIA ASSOCIADA À UNIVERSIDADE DE SÃO PAULO

\title{
AVALIAÇÃO DO DISPOSITIVO ELETRÔNICO DE IMAGEM PORTAL “PORTAL DOSIMETRY"NO CONTROLE DE QUALIDADE DE RADIOTERAPIA DE INTENSIDADE MODULADA
}

\author{
Érika Yumi Watanabe
}

Dissertação apresentada como parte dos requisitos para a obtenção do grau de Mestre em Ciências na Área de Tecnlogia Nuclear Aplicações

Orientadora: Profa. Dra Laura Natal Rodrigues

São Paulo 


\section{Agradecimentos}

Especialmente a minha orientadora Prof ${ }^{\text {a }}$. Dra. Laura Natal Rodrigues pelos ensinamentos fundamentais, orientação, apoio, paciência e confiança que foram fundamentais para a realização deste trabalho.

Às amigas Monica Lagatta e Sandra Regina de O. Borges pela enorme paciência, cooperação e suporte desde o início.

À Ana Maria T. Pires por ter permitido flexibilidade nos horários de trabalho para que eu pudesse concluir as disciplinas.

À equipe de física do Hospital Israelita Albert Einstein pelos ensinamentos, incentivos e por terem sido fonte de inspiração para execução deste trabalho.

Aos meus pais Elizio Tossio Watanabe e Elisabeth Andrade Watanabe pelo incentivo desde sempre.

Ao meu afilhado e sobrinho Vinícius Cardoso Watanabe por despertar em mim um sentimento de amor incondicional e por proporcionar momentos de alegria em diversas situações em minha vida, mesmo à distância.

Aos meus irmãos Eduardo Andrade Watanabe, Elisângela Andrade Watanabe e Edwin Hideki Watanabe pelo carinho, apoio e por serem exemplos de pessoas para mim.

Ao Hospital Alemão Oswaldo Cruz pela oportunidade de utilizar as instalações para realizar as medidas necessárias.

A todos os amigos, colegas e profissionais que contribuíram direta ou indiretamente para a realização dessa dissertação de mestrado. 


\title{
AVALIAÇÃO DO DISPOSITIVO ELETRÔNICO DE IMAGEM PORTAL "PORTAL DOSIMETRY"NO CONTROLE DE QUALIDADE DE RADIOTERAPIA DE INTENSIDADE MODULADA.
}

\author{
ÉRIKA YUMI WATANABE
}

\section{RESUMO}

No presente trabalho serão apresentados testes de comissionamento e de avaliação da utilização do portal dosimetry, da Varian, no controle de qualidade dos planejamentos de radioterapia de intensidade modulada. Os testes de comissionamento foram realizados para caracterizar o portal dosimetry em termos dosimétricos e para avaliar a sua possível aplicação em radioterapia. Esses testes demonstraram que o portal dosimetry possui todas as características necessárias para ser utilizado em dosimetria na radioterapia tais como linearidade da resposta com a dose, independência com a taxa de dose, reprodutibilidade, dentre outras. A avaliação da utilização do portal dosimetry no controle de qualidade de IMRT foi realizada em duas etapas: avaliação da capacidade do dispositivo em detectar erros propositalmente introduzidos em fluências simples e em fluências complexas. Foram introduzidos erros de magnitude conhecida em áreas determinadas das fluências e foi realizado o controle de qualidade dessas fluências com o portal dosimetry e com mais três sistemas dosimétricos: câmara de ionização, filme e matriz de câmaras de ionização. Os dados obtidos com o portal foram comparados com os dos outros dispositivos e todos foram capazes de identificar os erros introduzidos de maneira satisfatória, sendo os valores, normalizados para a fluência original, obtidos com o dosímetro portal indênticos aos da câmara de ionização e aos da matriz de câmaras de ionização (seven29) e diferindo em até $2 \%$ dos valores obtidos com os filmes. As fluências medidas com o portal dosimetry foram avaliadas em termos quantitativos e qualitativos. Os índices da função gama fornecidos pelo software de análise do portal dosimetry não apresentaram regras definidas de comportamento em relação aos erros introduzidos e por essa razão a análise qualitativa se mostrou indispensável nos casos avaliados. 


\title{
EVALUATION OF ELECTRONIC IMAGING DEVICE PORTAL "PORTAL DOSIMETRY" IN QUALITY CONTROL IN INTENSITY MODULATED RADIOTHERAPY.
}

\section{ERIKA YUMI WATANABE}

\begin{abstract}
In this paper we present commissioning testing and evaluation of the use of Varian's portal dosimetry in the quality assurance of intensity-modulated radiotherapy. The commissioning tests were performed to characterize the portal dosimetry in terms dosimetric and to assess the its possible application in radiotherapy. These tests demonstrated that portal dosimetry has all the characteristics to be used for dosimetry in radiotherapy such as linear response with dose, the independence of dose rate, reproducibility, and others. The evaluation of the use of portal dosimetry in quality control of IMRT was performed in two steps: assessing the ability of the device to detect errors deliberately introduced in simple and complex fluences. Errors of known magnitude were introduced in certain areas of fluences and was carried out quality control of these fluences with portal dosimetry and three dosimetric systems: ionization chamber, film and array of ionization chambers. The data obtained from the portal were compared with those of other devices and all were able to identify errors introduced satisfactorily, the values, normalized to the original fluence, obtained with the portal dosimetry were similar to the ionization chamber and the array of ion chambers (seven29) and differing in up to $2 \%$ of the values obtained with the films. The fluences measured with the portal dosimetry were evaluated both quantitatively and qualitatively. The index of the gamma function provided by software analysis of portal dosimetry showed no defined rules of behavior in relation to the errors introduced and for this reason the qualitative analysis has proved indispensable in cases evaluated.
\end{abstract}




\section{Sumário}

\section{Página}

1 INTRODUÇÃO ....................................................................................

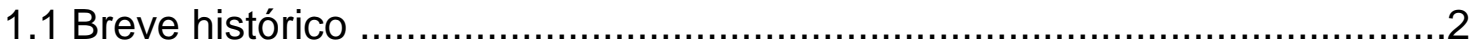

1.2 Fundamentos teóricos ........................................................................

1.2.1 Radioterapia de intensidade modulada

1.2.2 Controle de qualidade dos sistemas de planejamento

1.2.3 Função gama

1.2.4 Portal dosimetry

1.2.4.1 Aquisição

1.2.4.2 Previsão de dose

1.2.4.3 Módulo de análise

\section{OBJETIVOS}

\section{REVISÃO DA LITERATURA}

\section{MATERIAIS E MÉTODOS}

4.1 Testes de comissionamento

4.1.1 Calibração mecânica do braço

4.1.2 Calibração do Portal vision

4.1.3 Linearidade da resposta do portal dosimetry com a dose

4.1.4 Dependência direcional / Efeito da gravidade

4.1.5 Resposta do portal dosimetry em função da distância

4.1.6 Reprodutibilidade da resposta do portal dosimetry

4.1.7 Uniformidade da resposta ao longo da área ativa do dispositivo

4.1.8 Efeito de memória nos detectores do portal dosimetry

4.1.9 Influência da taxa de dose na resposta do portal dosimetry

4.2 Avaliação das Fluências

\section{RESULTADOS E DISCUSSÃO}

5.1 Comissionamento

5.1.1 Linearidade da leitura com a dose 
5.1.2 Dependência direcional

5.1.3 Resposta do portal dosimetry em função da distância

5.1.4 Reprodutibilidade da resposta do portal dosimetry

5.1.5 Uniformidade da resposta ao longo da área ativa do dispositivo

5.1.6 Efeito de memória nos detectores do portal dosimetry

5.1.7 Influência da taxa de dose na resposta do portal dosimetry

5.2 Avaliação das Fluências

5.2.1 Fluências simples

5.2.2 Avaliação das fluências complexas

6 CONCLUSÕES

REFERÊNCIAS 


\section{INTRODUÇÃO}

\subsection{Breve histórico}

A radioterapia é um tipo de tratamento que utiliza radiações ionizantes e seu desenvolvimento ocorreu em conseqüência de três descobertas: dos raios- $X$, da radioatividade e do elemento rádio ${ }^{1}$. Em janeiro de 1896, somente um ano após a descoberta dos raios- $X$, a primeira paciente portadora de um câncer de mama foi tratada com finalidade terapêutica ${ }^{1}$. A partir daí o uso da radiação ionizante em tratamentos de doenças malignas ou benignas cresceu juntamente com o desenvolvimento das técnicas de aplicação da radiação no paciente. Em 1902, começou a preocupação de se realizar dosimetrias visando a segurança e proteção do paciente e dos funcionários envolvidos nos procedimentos utilizando radiações ionizantes ${ }^{1}$.

A radioterapia pode ser dividida em duas grandes classes: a teleterapia, na qual a fonte de radiação é colocada a uma determinada distância do alvo de tratamento; e a braquiterapia, na qual a fonte de radiação é inserida muito próxima ao alvo de tratamento, ou seja, a fonte é colocada internamente ou na superfície do paciente e a distância até o alvo é muito pequena. Neste trabalho será abordada a técnica específica de teleterapia.

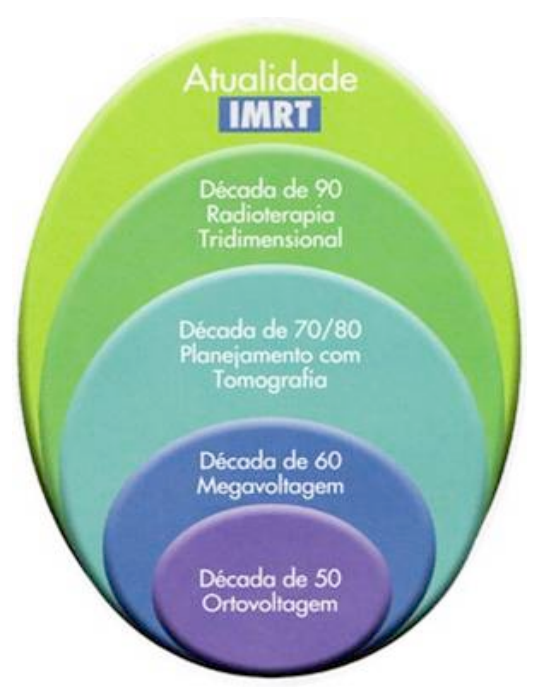

Figura1: Evolução da Radioterapia - Fonte: http://www.drmarclei.com.br/texto_tec.htm (último acesso em jan/2010). 
A teleterapia teve início com a utilização de equipamentos de raios- $X$ superficiais, em seguida vieram as máquinas de raios- $X$ de ortovoltagem, seguidos dos bétatrons, das máquinas que utilizam isótopos e, por fim, dos aceleradores lineares (Figura 2).

A radioterapia moderna acompanhou a evolução ocorrida na informática e devido a pesquisas na área de planejamentos computacionais inversos, utilizando o conceito de campos segmentados, em 1996 foi introduzido a técnica de Radioterapia com Intensidade Modulada (IMRT) por Thomas Bortfeld e Steve $W \mathrm{Wbb}^{2}$. Esta técnica utiliza campos de intensidade modulada que, quando combinados, podem proporcionar uma redução substancial da dose em tecidos sadios adjacentes a regiões de altas doses que contém tecidos tumorais ou áreas de possível infiltração tumoral ${ }^{3-4}$.
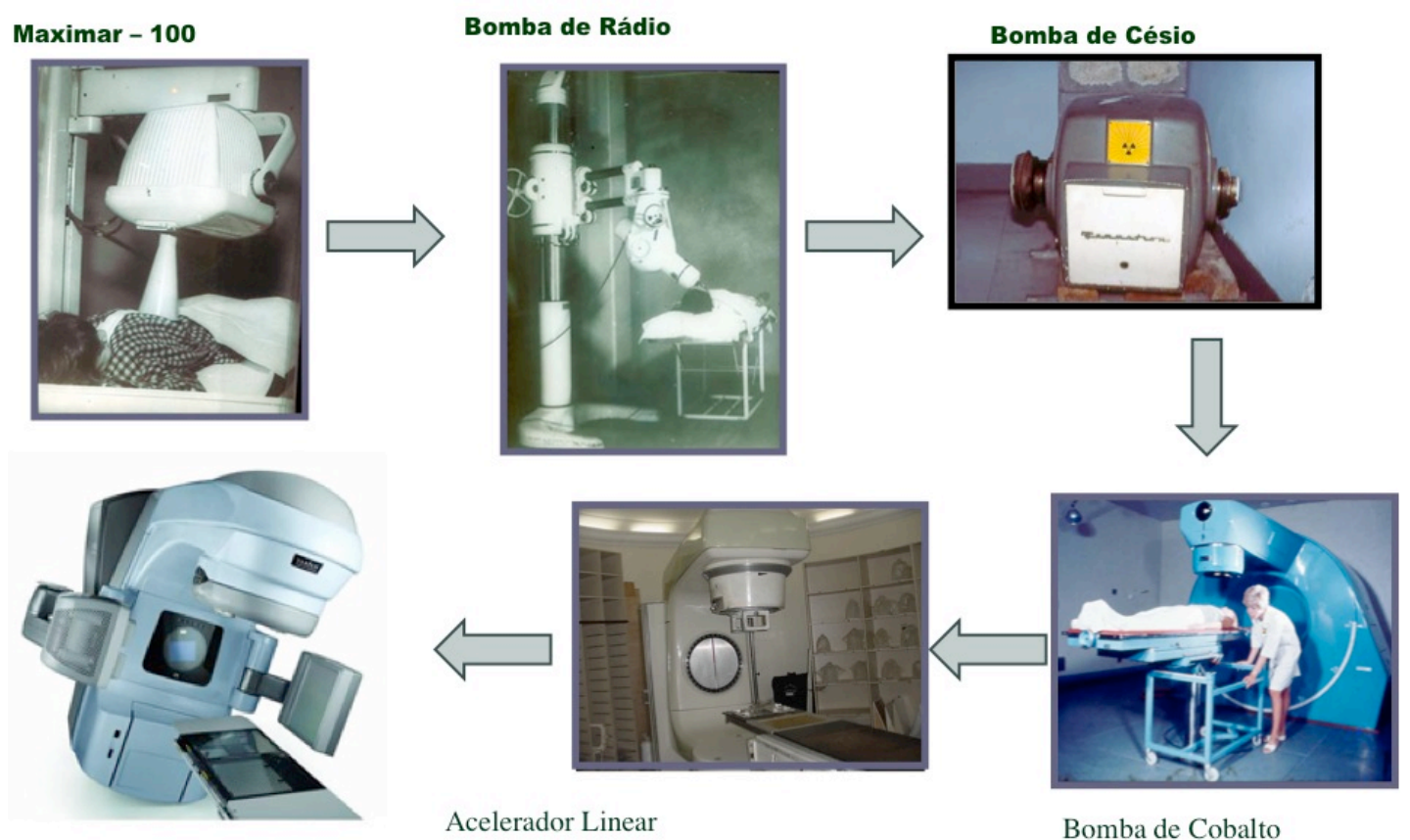

Acelerador Linear

Bomba de Cobalto

Figura 2: Evolução dos equipamentos utilizados em Radioterapia

A IMRT é uma técnica bastante complexa, onde cada campo pode ser segmentado em até 300 sub-campos, impossibilitando uma verificação manual do cálculo de unidades monitoras, conforme é feito rotineiramente em um tratamento convencional, por isso há a necessidade de se realizar um controle de qualidade (CQ) rigoroso do plano dosimétrico prévio ao tratamento do paciente ${ }^{5}$. Esse 
controle é feito em duas etapas: a verificação da dose absoluta pontual em um objeto simulador, liberando um campo por vez ou todos os campos; e a verificação das fluências planares individuais de cada campo modulado ${ }^{6}$, comparando-se com a dose calculada no sistema de planejamento. Para a verificação das fluências podem ser utilizados filmes dosimétricos, ou dispositivos eletrônicos desenvolvidos para isso, tal como os dispositivos eletrônicos de imagem portal (EPID) e dosímetros de múltiplas câmaras ${ }^{7}$. O método que utiliza filmes é o mais tradicional, porém, não permite uma análise imediata dos resultados, necessitando que os filmes sejam revelados e digitalizados para posterior análise em softwares adequados, sendo que o processo de revelação e digitalização introduz grandes incertezas. Os EPID produzem imagens digitais de alta resolução, sendo possível a avaliação em um ambiente integrado, ou seja, a aquisição, o manuseio e a análise das imagens é realizada em um mesmo software, dispensando a necessidade de etapas intermediárias que podem interferir nos resultados, alem de reduzir o tempo envolvido no processo. ${ }^{8-9}$

Dentre os dispositivos utilizados para o controle de qualidade de IMRT planar destacam-se: o 2D Array seven29 (PTW) que é uma matriz de 729 microcâmaras de ionização ${ }^{9-10}$ e o Dosímetro Portal (Portal Dosimetry - PD), que consiste em uma matriz de detectores de silício amorfo (aSi $)^{11-13}$. Ambos os dispositivos dosimétricos permitem a realização do controle de qualidade de planos de IMRT de uma maneira rápida e prática, diminuindo assim a carga de trabalho do físico nesses tipos de tratamento.

A análise dos controles de qualidade realizados com esses dispositivos eletrônicos pode ser feita qualitativamente, ou seja, através de uma comparação visual das fluências medidas e calculadas, ou, quantitativamente, através de funções matemáticas comparativas desenvolvidas para esse fim ${ }^{14}$. A análise quantitativa vem sendo amplamente explorada a fim de se determinar parâmetros que comprovem a correlação entre um determinado plano de tratamento e sua administração na máquina durante o controle de qualidade ${ }^{15}$. A principal função utilizada para analisar o controle de qualidade quantitativamente é a função gama $^{16}$. Essa função relaciona dois parâmetros principais que, para cada ponto medido em um plano, quando comparado com o plano calculado, quantifica-se a diferença de dose e a distância no plano até encontrar um outro ponto de mesma dose ${ }^{17-18}$. É uma ferramenta particularmente útil para avaliar regiões de grandes 
gradientes de dose, bastante comuns em campos modulados de IMRT.

Alguns EPIDs disponíveis comercialmente são acompanhados por softwares que oferecem essas funções quantitativas de análise, porém há a necessidade de estudos que verifiquem se os parâmetros indicados no software são realmente capazes de identificar possíveis erros na entrega da dose, e que analisem os parâmetros quantitativos de maneira que seja possível identificar e determinar parâmetros que possam ser universalmente utilizados no critério de aprovação do plano de tratamento.

\subsection{Fundamentos Teóricos}

\subsubsection{Radioterapia de Intensidade Modulada}

As tecnologias envolvidas no planejamento e na entrega da dose em radioterapia têm mudado constantemente. Essas mudanças visam um maior benefício do paciente, porém cada mudança traz consigo um espectro de novos conceitos sobre sua aplicação apropriada na prática da radioterapia.

A modulação da intensidade na entrega da radiação tem mudado radicalmente a radioterapia e tem expandido grandemente as oportunidades da especialidade. Um pouco mais de uma década atrás, a IMRT era uma idéia nova e não convencional. Em 1996, os colimadores multi-lâminas foram adaptados para a IMRT ${ }^{19}$. No começo de 2000 a experiência adquirida trouxe confiança para que a IMRT pudesse ser utilizada rotineiramente desde que os controles de qualidades apropriados fossem realizados ${ }^{20}$.

Em um planejamento de IMRT, o sistema de planejamento computacional executa uma série de rotinas para encontrar a melhor a solução da distribuição dos pesos para os campos. No sistema de planejamento de IMRT da Varian (Eclipse) alguns valores matemáticos devem ser estabelecidos antes do início da otimização, os quais são denominados "constraints" ou limites de dose. Existem também outros dados que devem ser inseridos no sistema de planejamento, tais como os limites de dose-volume, sendo que o objetivo é tal que nada além de uma dada percentagem $x$ de um órgão, em volume, receba uma dose y. O Eclipse 
irá tentar atingir os objetivos para o histograma dose-volume (DVH), que é a representação gráfica da distribuição de dose em um planejamento, ilustrando a quantidade de dose recebida por determinado volume.

Uma vez estabelecidos os limites de dose, o programa executa uma série de sub-rotinas para que a diferença quadrática média entre a dose de prescrição do alvo e a dose prevista pelo sistema de planejamento seja a menor possível, através das mudanças dos pesos relativos utilizando uma função objetiva.

A função objetiva é uma soma ponderada dos termos para os tecidos normais e para o volume alvo. Diferentes termos têm diferentes pesos multiplicativos, especificando a importância relativa desses termos ${ }^{21}$.

Uma equação matemática que é freqüentemente utilizada em IMRT é a função objetiva chamada de "generalized equivalent uniform dose" (GEUD). Essa função fornece a distribuição de dose em uma dada estrutura ${ }^{22}$, sendo $\mathrm{N}=$ número de voxels na estrutura de interesse; $d i=$ dose do voxel i; a = variável do parâmetro exponencial.

$$
\text { GEUD }=\left\{\frac{1}{N} \sum_{i=1}^{N} d_{i} \times d_{i}^{(\mathfrak{a}-1)}\right\}^{1 / \mathfrak{a}},
$$

Após a especificação da função objetiva, os campos são mapeados em pequenos elementos discretos denominados de "beamlets" e o objetivo do programa passa a ser encontrar o peso ótimo de cada "beamlet" para que sejam atingidos os limites de dose e a dose de prescrição.

$\mathrm{Na}$ prática, a grande vantagem da modulação do feixe de radiação é a possibilidade de se obter uma distribuição de dose muito mais bem conformada no alvo, como pode ser visto na figura 3, e poupar mais os órgãos de risco próximos ao alvo, mesmo entregando uma dose total de radiação mais alta.

Para implementar a IMRT, deve ser feito um controle de qualidade especifico para cada paciente deve ser feito, sendo um processo adicional mas de grande importância. Conforme aumenta a experiência do usuário com a utilização das ferramentas de planejamento dessa técnica, o tempo necessário para realizar um plano de IMRT diminui significativamente, permitindo às clínicas tratar um número maior de pacientes, porém o número de controles de qualidade 
a serem feitos também aumenta proporcionalmente. Os resultados clínicos dão suporte ao uso da IMRT para vários tipos de câncer. Em muitos casos, eles mostram que o aumento da dose no tumor pode aumentar as taxas de controle local e diminuir a dose em tecidos normais, reduzindo complicações ${ }^{23}$.

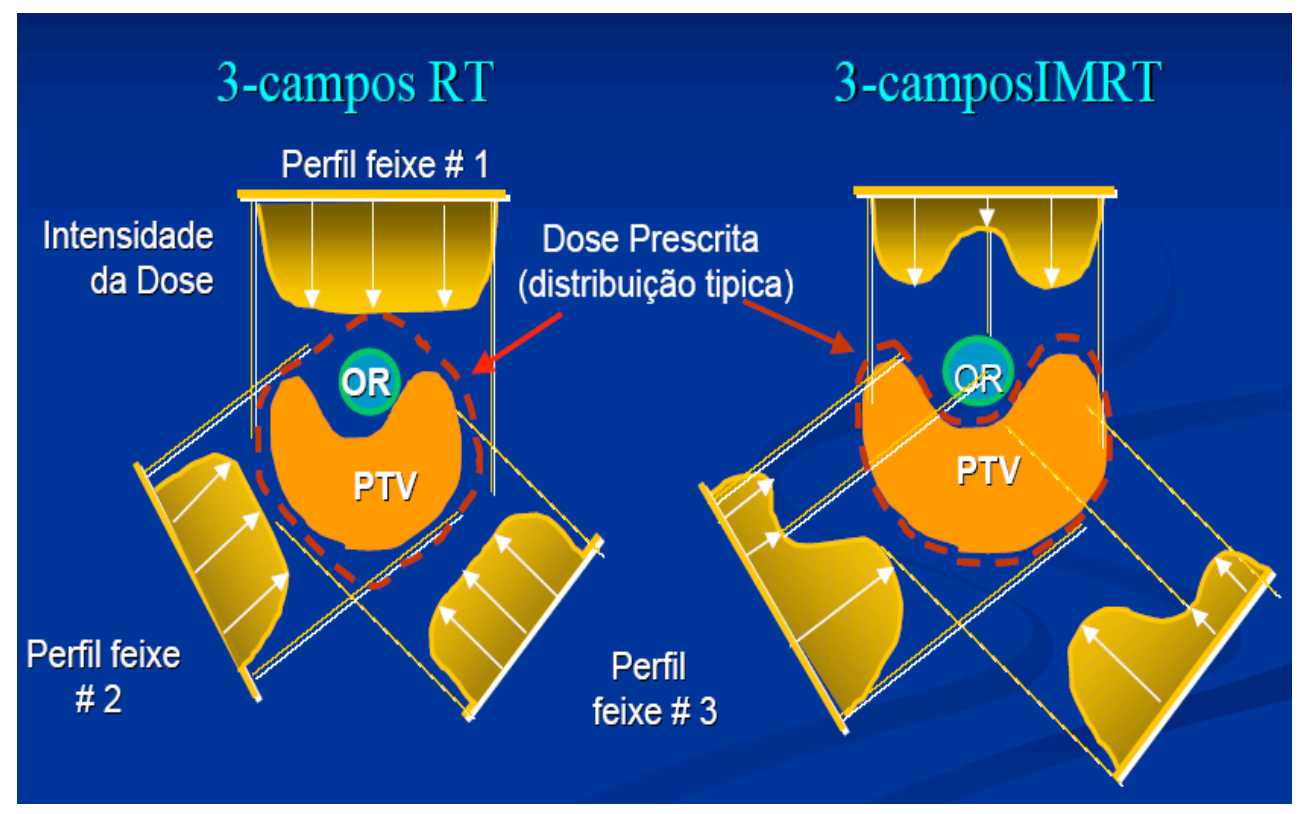

Figura 3: llustração da melhor conformidade obtida com a técnica de IMRT.

\subsubsection{Controle de Qualidade dos sistemas de planejamento}

A evolução da radioterapia implica na utilização de sistemas de planejamentos cada vez mais complexos, incluindo novas ferramentas e novos algoritmos de cálculo. Por essa razão o controle de qualidade dos sistemas de planejamentos se faz necessário.

Existem documentos que orientam o modo como esses controles de qualidade dos sistemas de planejamento devem ser feitos, como por exemplo os TecDocs $1540^{24}$ e $1583^{25}$, o TRS $-430^{26}$ da Agência Internacional de Energia Atômica (AIEA) e o TG-53 ${ }^{27}$ da Associação Americana de Física Médica (AAPM). 


\subsubsection{Função gama}

O método de análise gama, como apresentado por Low e colaboradores ${ }^{28}$, é uma comparação quantitativa entre duas distribuições de dose. Uma análise qualitativa visual não seria suficiente para a comparação das distribuições de dose, pois sérios erros podem facilmente passar desapercebidos se a comparação não for realizada quantitativamente.

Van Dyk e colaboradores ${ }^{29}$ descreveram os procedimentos de controle qualidade de sistemas de planejamento de tratamento e subdividiram as comparações de distribuições de dose em regiões de alto e baixo gradiente, cada um com um critério diferente de aceitação. Em regiões de baixo gradiente, as doses são comparadas diretamente, com uma tolerância baseada na diferença entre as doses medidas e calculadas. Em regiões de alto gradiente, um pequeno erro espacial, tanto na fluência calculada quanto na medida, resulta em uma grande diferença de dose entre os pontos. Por essa razão, diferenças de dose em regiões de alto gradiente podem ser relativamente irrelevantes e o conceito de distância para concordância (DTA) é usado para determinar a aceitação da dose calculada. A DTA é a distância entre um dado ponto de medida e o ponto mais próximo na distribuição de dose calculada que exibe a mesma dose.

A análise gama é baseada na função que foi desenvolvida para unificar as comparações de distribuições de dose utilizando um determinado critério de aceitação. Essa função considera tanto o valor da dose quanto a distância entre os pontos (DTA) que estão sendo avaliados, ou seja, a partir de um sistema de coordenadas espaciais, o critério de aceitação forma uma superfície elipsóide cujo centro é o ponto de medida em questão. O principal parâmetro dessa função é o de índice gama $(\gamma)$ que corresponde a distância mínima radial entre o ponto de medida e o ponto de cálculo. A análise gama consiste em avaliar as regiões onde $\gamma>1$, pois elas correspondem a locais onde os pontos avaliados apresentam diferenças além da tolerância estabelecida.

A análise de uma distribuição de dose de planejamentos complexos tais como as fluências obtidas com IMRT se torna bastante difícil, pois pode haver regiões de altos e baixos gradientes de dose . 


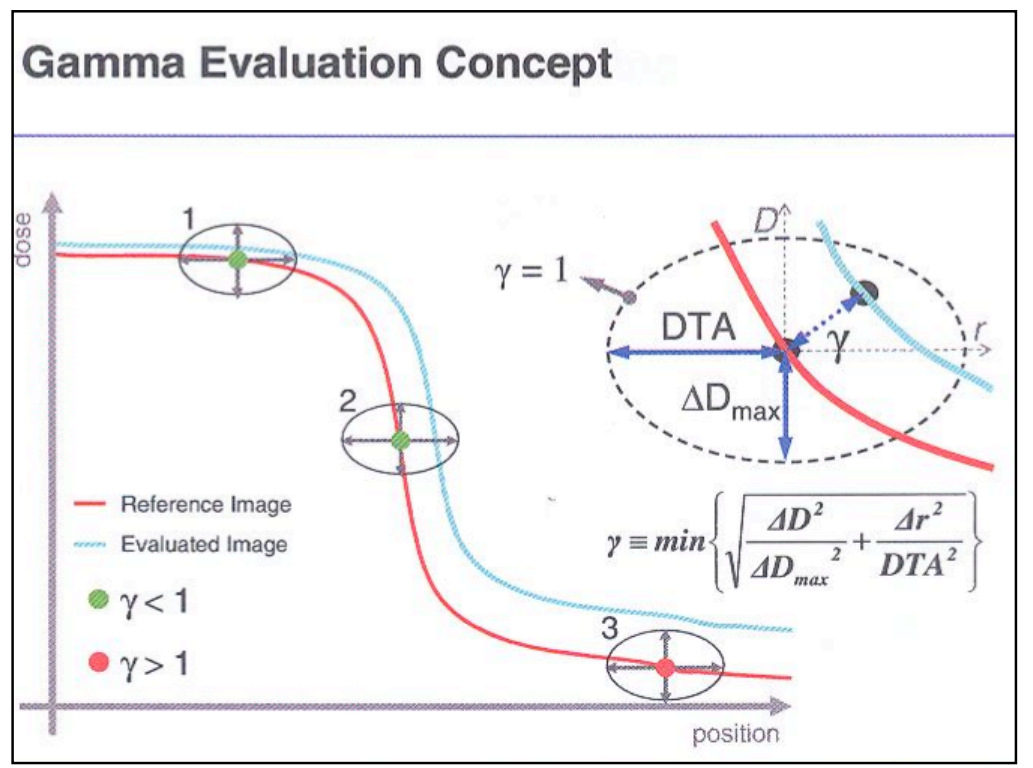

Figura 4: Ilustração do conceito da análise gama. A curva vermelha representa a imagem de referência e a azul, a imagem analisada - Fonte: Varian Medical Systems, Reference Guide for Portal Dosimetry.

A importância da análise gama está na determinação da qualidade da medida, através do índice $\gamma$, que indica a diferença entre os valores esperados e os medidos relativamente aos critérios de aceitação. Um gráfico do índice gama de cada ponto de uma determinada fluência é uma ferramenta importante para a análise quantitativa de um planejamento de tratamento.

\subsubsection{Dosimetria portal (Portal Dosimetry)}

O "portal dosimetry" (PD) é um sistema de alta resolução designado para realizar o controle de qualidade de planejamentos de IMRT através da verificação de dose em duas dimensões, para cada campo de tratamento. O método de verificação do plano é baseado na análise da concordância dos valores calculados (previstos) com os valores medidos. (Figura 5) 


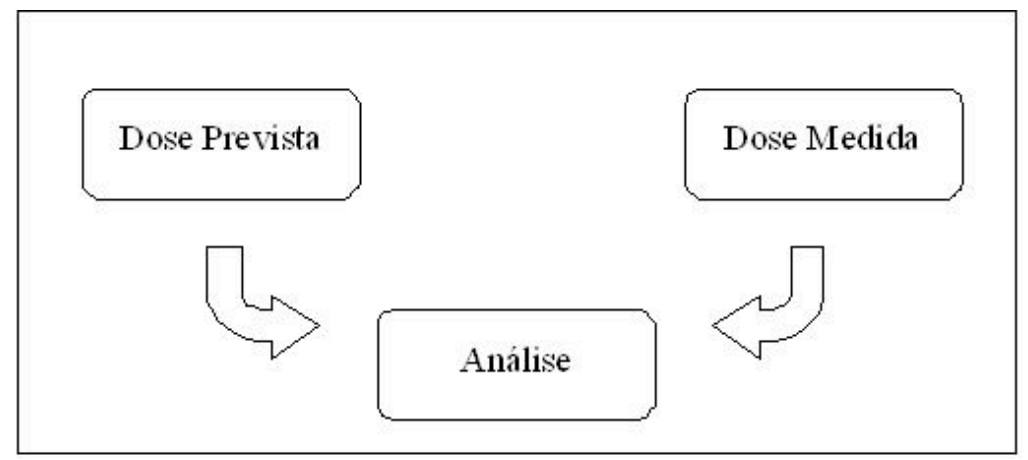

Figura 5: llustração do método de verificação do plano com o PD.

O "portal dosimetry" faz parte de um sistema que consiste de um programa de planejamento de tratamento capaz de fornecer a dose prevista, de um sistema de aquisição de imagem (IAS) capaz de adquirir imagens de dose e de um módulo de análise (Review) para comparação das imagens dosimétricas. A arquitetura do sistema pode ser vista na Figura 6.

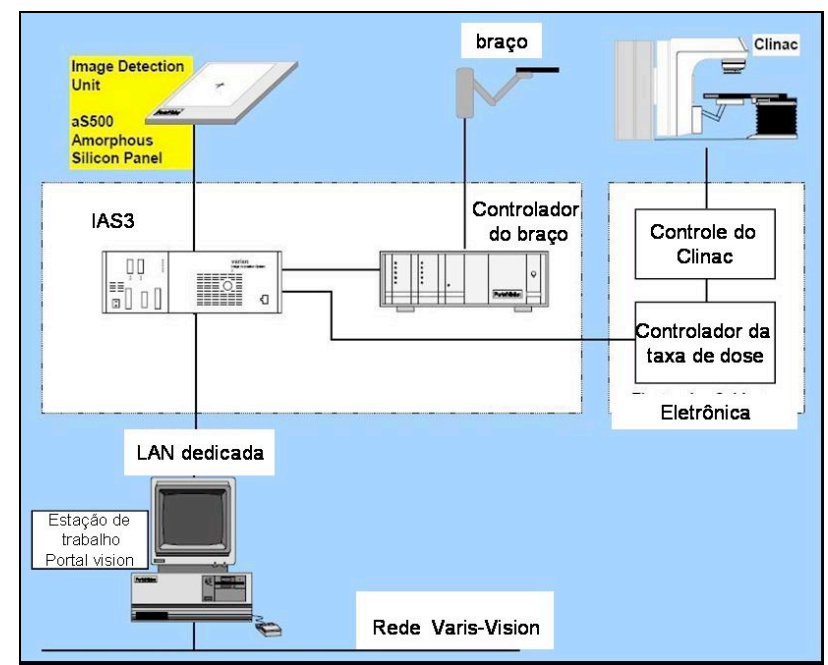

Figura 6: Visão geral do sistema do dispositivo portal.

Três componentes principais compõem o portal dosimetry: aquisição (Hardware e Software), predição de dose e Módulo de análise, os quais serão explicados a seguir. 


\subsubsection{Aquisição}

O "portal dosimetry" é montado em um braço robótico (Exact Arm) no acelerador linear, como pode ser visto na Figura 7. Esse braço robótico é utilizado para posicionar a unidade detectora de imagem (IDU) e permite que o dispositivo seja totalmente integrado ao acelerador linear. A área sensível do imageador é de $40 \mathrm{~cm} \times 30 \mathrm{~cm}$ e a matriz ativa consiste de $512 \times 384$ pixels, de modo que o tamanho de cada pixel é de $0,78 \mathrm{~mm} \times 0,78 \mathrm{~mm}$.

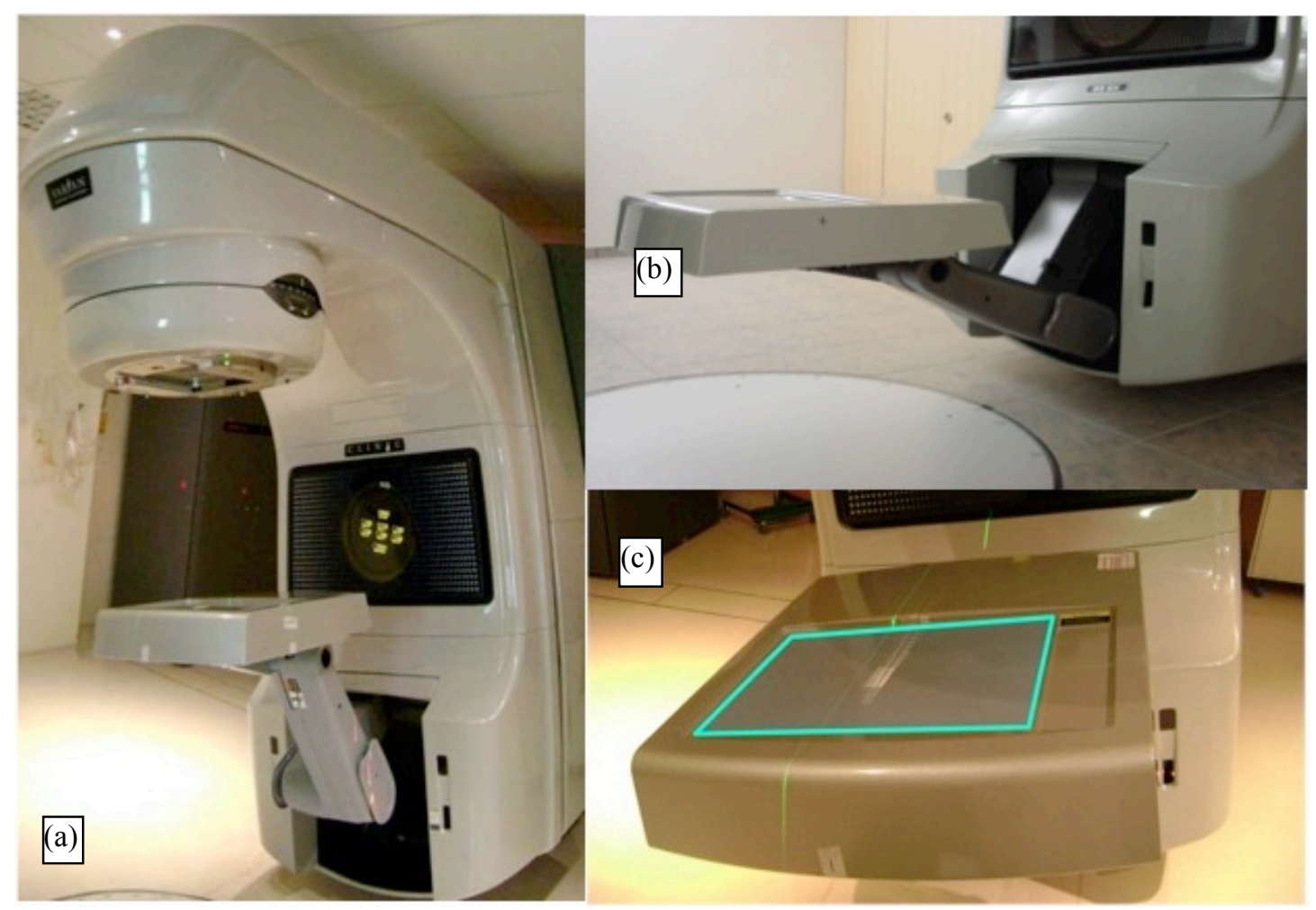

Figura 7: (a) Acelerador Linear com portal dosimetry integrado; (b) Portal Dosimetry em destaque; (c) Área ativa do dispositivo de dosimetria portal.

O imageador (Figura 8) é composto dos seguintes componentes: uma placa de $1 \mathrm{~mm}$ de cobre para prover o "build-up" e absorver a radiação espalhada; uma tela cintiladora de fósforo feita de térbio para converter a radiação incidente em fótons ópticos; uma matriz de pixels onde cada pixel é constituído de um fotodiodo e um transistor de filme fino (TFT); (Figura 9) uma eletrônica associada para a leitura da carga dos transistores e para a transformação em dados de imagem. Externamente, o imageador é envolto por uma capa de plástico protetora. 


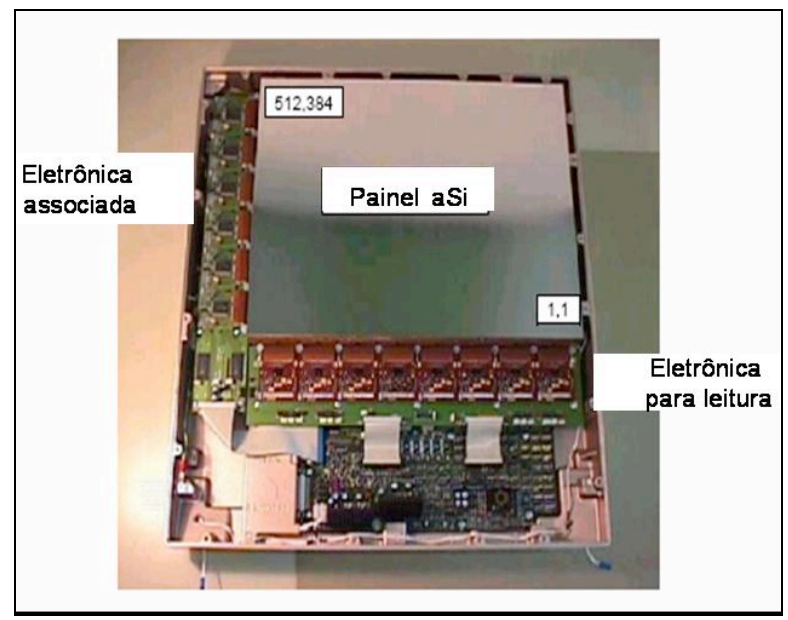

Figura 8: llustração do PD aSi500ll sem a capa de proteção.

O "build-up", que é a espessura necessária para que se tenha a dose máxima da matriz ativa dos detectores, é equivalente a $0,8 \mathrm{~cm}$ de água. Isso significa que a dose máxima não será atingida para as energias de $6 \mathrm{MV}$ e $16 \mathrm{MV}$, cujas espessuras de "build-up" são $1,5 \mathrm{~cm}$ e $3,0 \mathrm{~cm}$ respectivamente. Tais espessuras foram estudadas por vários pesquisadores e não influenciam em medidas relativas, sendo que o algoritmo de cálculo considera o "build-up" efetivo do $E_{P I D}^{30}$.

A imagem proveniente da leitura da matriz dos detectores é chamada de "frame". Essa leitura é realizada linha por linha da matriz através da transferência da carga dos fotodiodos para os amplificadores e da subseqüente conversão em um sinal digital.

Feixe de fótons

\begin{tabular}{|c|}
\hline Metal \\
\hline Fósforo \\
\hline Placa de a-Si \\
\hline
\end{tabular}

Figura 9: Ilustração da seção transversal do build-up do dispositivo composto por uma camada de metal, seguida por uma camada de fósforo e pela placa de semicondutores de amorfo-sílicio. 
O imageador é parte de um sistema maior, o Sistema de Aquisição de Imagem 3 (IAS3). Esse sistema possui componentes eletrônicos necessários para a aquisição, display e armazenamento de imagens incluindo a sincronização com o acelerador linear. (Figura 10)

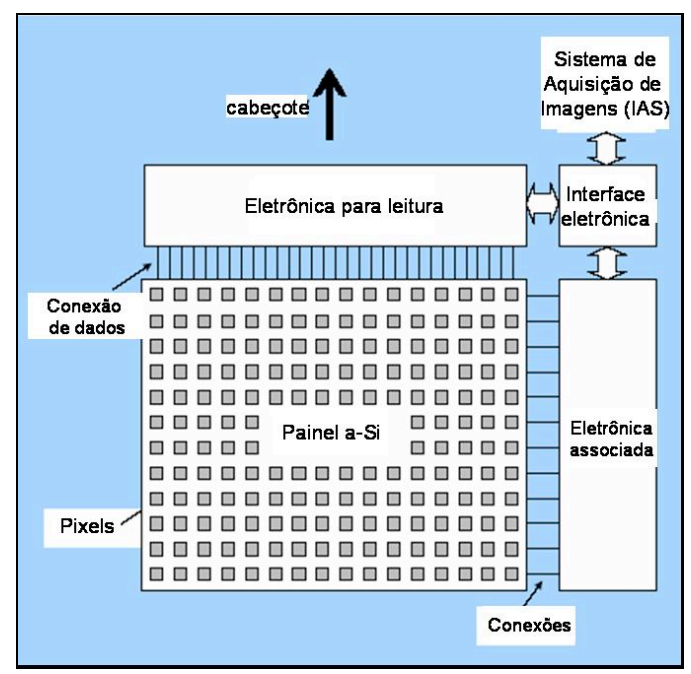

Figura 10: Ilustração da unidade de detecção de imagem (IDU).

No sistema de aquisição de imagem (Figura 11), a imagem é enviada como um sinal analógico do imageador para a unidade de digitalização (DU), onde ela é transformada em um sinal digital. Esse sinal é transferido para uma placa de controle universal (UCB) na Workstation Vision. O software Vision é uma família de produtos usados para gerenciar imagens e informações relacionadas. No cartão UCB, os dados são convertidos em um formato de vídeo padrão. O UCB também sincroniza o imager, a DU e o acelerador. A sincronização é diferente dependendo do tipo de imagem a ser adquirida. Para imagens dosimétricas, que são integradas durante a entrega de cada campo de tratamento, as informações são obtidas entre os pulsos do feixe. Para imagens não dosimétricas, usadas para verificação do posicionamento, os pulsos do feixe são mantidos por um período curto de tempo para permitir a leitura de todo o imageador.

A imagem é transferida do UCB para a placa de processamento de frames (FPB). A FPB processa e calibra a imagem e a imagem final é armazenada no servidor Vision e pode ser mostrada em qualquer estação de trabalho Vision. 


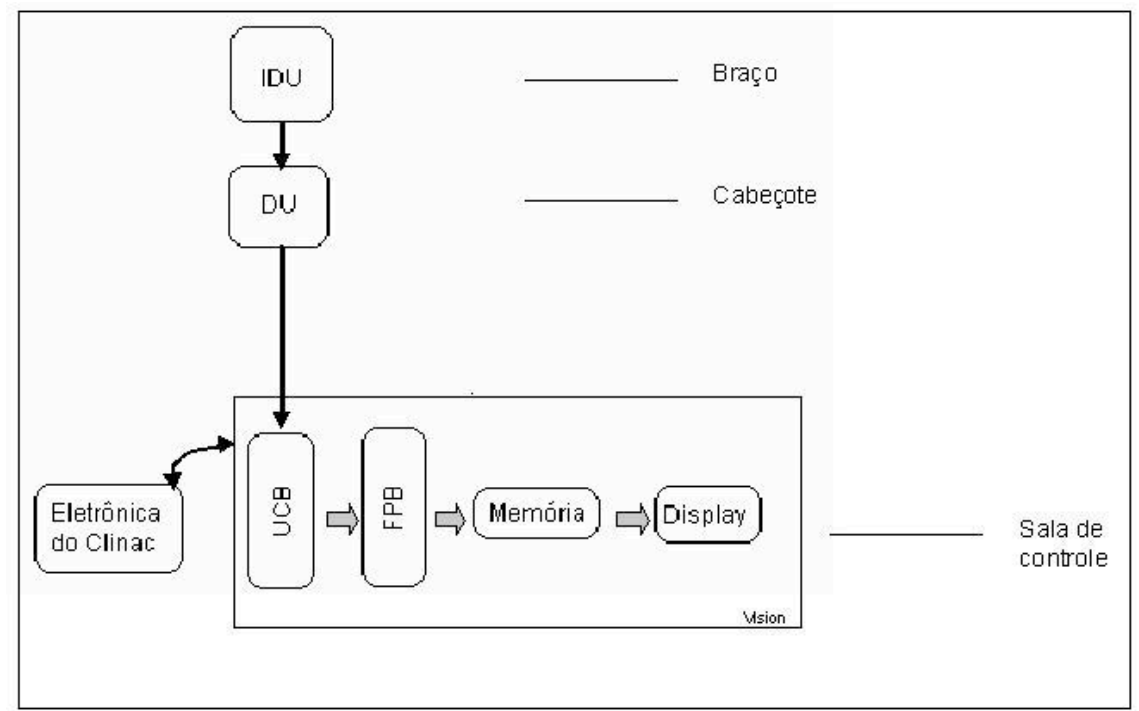

Figura 11: Diagrama esquemático do sistema de aquisição de imagens IAS3.

O programa de aquisição é o 4DTC (4D treatment console) e as imagens são armazenadas em uma base de dados VMS - Varian Medical System. Tanto o 4DTC quanto a base de dados VMS fazem parte do sistema integrado da Varian que inclui o portal dosimetry.

\subsubsection{Previsão de dose}

A previsão de dose é o cálculo da dose esperada pelo sistema de planejamento. O algoritmo de previsão de dose (PDC - Portal Dose Calculation) é parte do sistema de planejamento Eclipse, mas é um algoritmo independente e calcula o kernel específico para os detectores de silício amorfo, proporcionando uma modelagem do gradiente bastante precisa em relação as medidas realizadas. A dose da imagem portal ( $\left.\mathrm{I}_{\mathrm{PD}}\right)$ é calculada pela convolução da fluência $\left(\varphi_{\text {EPID }}\right)$, no plano do imageador, com a dose kernel (K):

$$
I_{P D}(x, y)=\phi_{E P I D}(x, y) \otimes \kappa
$$




\subsubsection{Módulo de análise}

O módulo de análise é um gerenciador de imagens que possui ferramentas de alinhamento e análise de imagens de dose tais como as funções gama e diferença de dose.

A análise da imagem dosimétrica, ou das fluências, pode ser realizada na tarefa Review dentro do próprio programa Eclipse. Esse módulo permite avaliar dose em um ponto, dose linear (perfis de dose), alinhamento da imagem e comparação de dose relativa e absoluta.

\section{REVISÃO DA LITERATURA}

A utilização do EPID no controle de qualidade de IMRT é relativamente recente. As características da resposta do EPID em função da dose de um EPID de aSi foram descritas por Winkler P. e colaboradores ${ }^{31}$ e por Greer P.B. e colaboradores $^{32}$ em termos da variação com a distância do raio central e dependência da energia para planejamentos de IMRT utilizando a técnica de "sliding window".

Os dispositivos de dosimetria eletrônica, tais como as matrizes bidimensionais de detectores, foram avaliados por Rosenfeld A.B. ${ }^{33}$ em termos de sua aplicabilidade em controle de qualidade em Radioterapia, sendo que eles utilizaram diversos dosímetros para a comparação das respostas obtidas tais como o mosfet e o diodo. Poppe B. e colaboradores ${ }^{34}$ também avaliaram esses dispositivos dando ênfase à análise da função gama. A validação e implementação da dosimetria portal com um EPID, foi publicada por Winkler P. e colaboradores ${ }^{35}$ para a faixa de energia de 6 a $25 \mathrm{MV}$.

Kavuma A. e colaboradores ${ }^{36}$ avaliaram a performance dosimétrica de onze EPIDs aSi 500 da VARIAN, em termos de uniformidade, linearidade, dependência direcional, efeito de memória, perfil, tamanho de campo e taxa de dose. Este trabalho será empregado para realizar a comparação e validação dos resultados 
obtidos na presente dissertação.

Em relação aos níveis de ação para controles de qualidade de IMRT

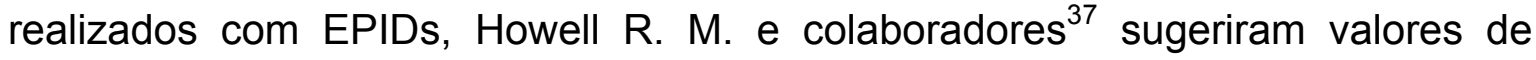
limites de ações.

\section{OBJETIVOS}

O objetivo deste trabalho é realizar testes de comissionamento do dispositivo eletrônico de imagem portal - Portal Dosimetry- e avaliá-lo no processo de controle de qualidade da radioterapia de intensidade modulada em termos quantitativos e qualitativos. 


\section{MATERIAIS E MÉTODOS}

\subsection{Testes de comissionamento}

Esses testes têm como objetivo avaliar as características do dispositivo em termos de resposta em função do feixe de radiação para assegurar que seu comportamento está conforme o esperado.

\subsubsection{Calibração mecânica do braço}

Antes de iniciar a utilização do PD, é necessária a calibração mecânica do braço (exact arm) do dispositivo para assegurar o correto posicionamento do mesmo em função da distância da fonte. Essa calibração é feita para determinar a posição original do imageador correspondente ao ponto $(0,0,0)$. Para a realização da calibração mecânica do braço é necessário retirar a capa de plástico protetora. A superfície do imageador possui uma demarcação que deve ser ajustada para coincidir com o centro do campo de radiação e o imageador deve ser posicionado de modo que os detectores ativos fiquem na distância fonte-isocentro do acelerador linear, ou seja, $100 \mathrm{~cm}$. Essa deve ser a distância da fonte até os detectores ativos, portanto a distância até a superfície da placa metálica deve ser de $98,8 \mathrm{~cm}$, pois existe $1,2 \mathrm{~cm}$ de material para prover o build-up (equivalente a $0,8 \mathrm{~cm}$ de água). (Figura 12)

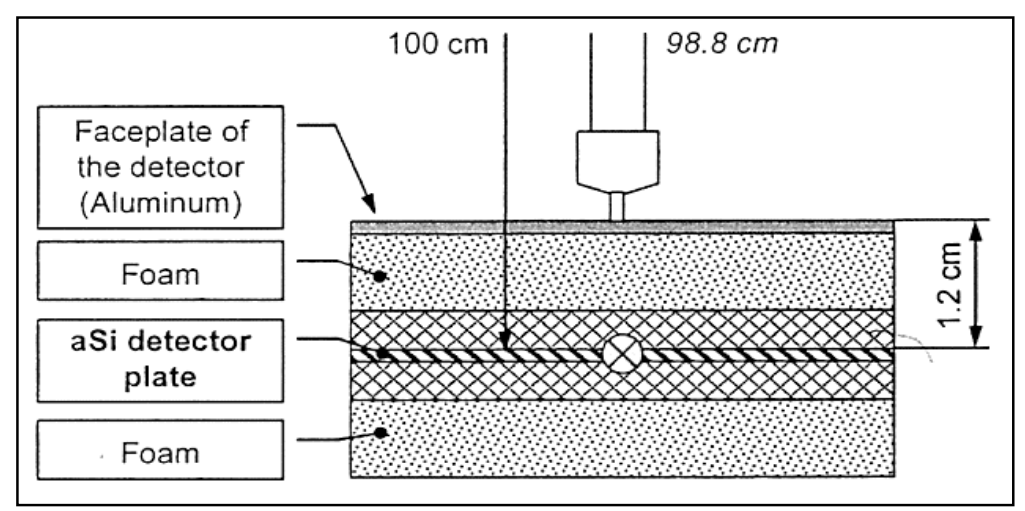

Figura 12: llustração do posicionamento do imageador para a calibração mecânica do braço. Fonte: Varian Medical System, Reference Guide for Portal Vision. 
Após o posicionamento correto do imageador, a calibração é realizada através da gravação dessa posição utilizando o controle remoto do PD (pendente). (Figura 13)

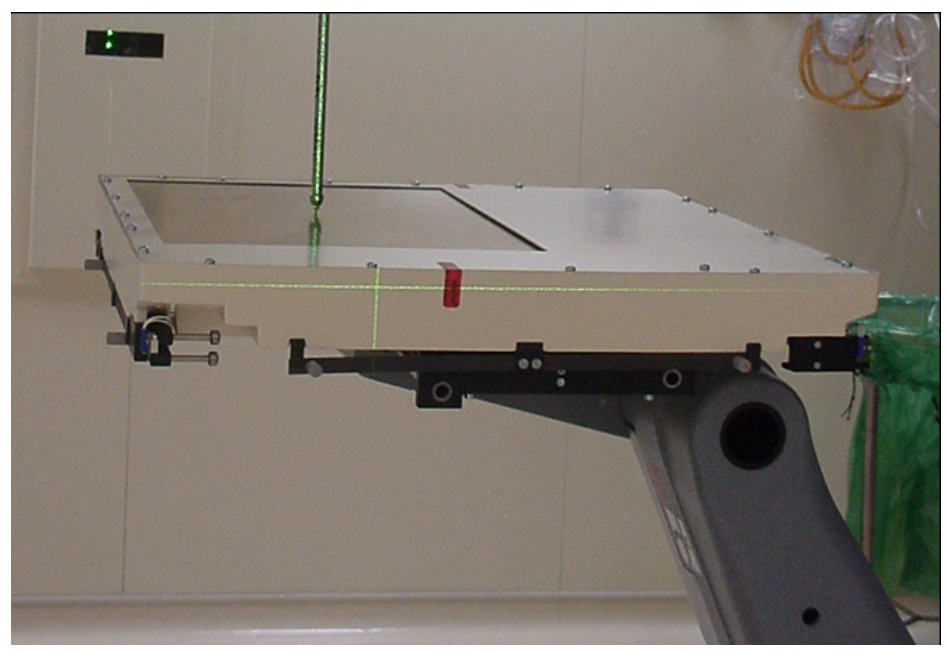

Figura 13: Posicionamento do imageador na distância de $98,8 \mathrm{~cm}$ medida com a ponteira devidamente calibrada.

\subsubsection{Calibração do Portal Vision}

A calibração do dispositivo portal consiste de duas etapas: a calibração do dispositivo em termos de aquisição da imagem e a calibração absoluta dos detectores. A primeira tem como objetivo garantir a qualidade da imagem adquirida e a segunda assegura a obtenção correta da dose correspondente.

A calibração do dispositivo em termos de imagem é realizada com a aquisição do "dark field" (DF) (Figura 14), para eliminar o ruído eletrônico e o background, e do "flood field" (FF), para corrigir variações na sensibilidade dos pixels. Estes dois parâmetros são adquiridos para todas as energias e taxas de dose disponíveis no acelerador linear. 


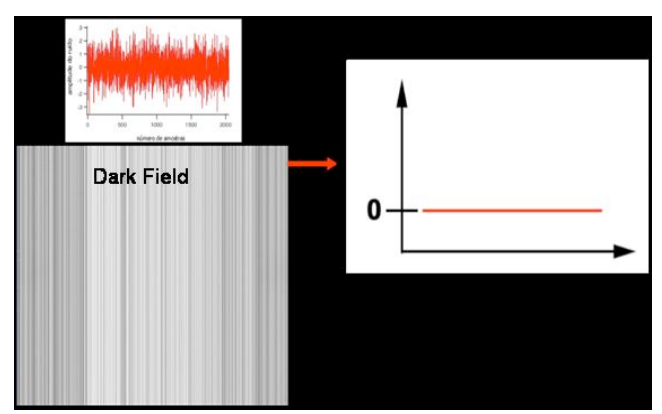

Figura 14: Ilustração do dark field para a diminuição do ruído. Fonte: Varian Medical System, Reference Guide for Portal Vision.

A calibração absoluta dos detectores consiste na atribuição de um valor de dose para cada unidade de calibração (UC), que é uma unidade específica do portal dosimetry da Varian. Essa calibração é realizada com um campo de radiação de $10 \times 10 \mathrm{~cm}^{2}$, 100UM (unidade monitora - UM é o parâmetro selecionado no acelerador linear que é diretamente proporcional a dose), e $\mathrm{SSD}=100 \mathrm{~cm}$, de modo que a dose entregue nessas condições seja igual a 100UCs. Portanto, a calibração estabelece que 1UC seja igual a 1cGy, assim como na calibração do acelerador linear.

Apos a calibração, as imagens dosimétricas foram adquiridas no modo integrado.

\subsubsection{Linearidade da resposta do portal dosimetry com a dose}

A calibração do PD tem como princípio a linearidade da resposta do PD com a dose e para avaliar esse comportamento fixou-se um campo de $10 \times 10 \mathrm{~cm}^{2}$, taxa de dose $=400 \mathrm{UM} / \mathrm{min}$ e o PD foi posicionado a uma distância fonte-superfície de $100 \mathrm{~cm}$. Obteve-se imagens dosimétricas integradas, para 6 e $16 \mathrm{MV}$ de fótons, para os seguintes valores de unidade monitora (UM): 1, 2, 5, 10, 20, 50, 100, 200, 500,900 . Os valores de resposta considerados foram obtidos na região central da imagem dosimétrica, ou seja, no ponto de origem $(0,0,0)$. 


\subsubsection{Dependência direcional / Efeito da gravidade}

O portal dosimetry pode adquirir imagens dosimétricas em diferentes ângulos de cabeçote, porém o efeito da gravidade pode interferir na estabilidade mecânica do EPID e, consequentemente, na resposta dos detectores. Avaliou-se esse efeito mantendo-se o dispositivo a uma distância fonte superfície fixa de 100 $\mathrm{cm}$, utilizou-se um campo de $10 \times 10 \mathrm{~cm}^{2}, 50 \mathrm{UM}$ e taxa de dose de $400 \mathrm{UM} / \mathrm{min}$. Os valores de resposta considerados foram obtidos do ponto $(0,0,0)$ das imagens obtidas variando-se o ângulo do cabeçote de $0^{\circ}$ a $345^{\circ}$ em intervalos de $15^{\circ}$ (Figura 15). Considerou-se o valor obtido da imagem com o cabeçote a $0^{\circ}$ como sendo a referência.

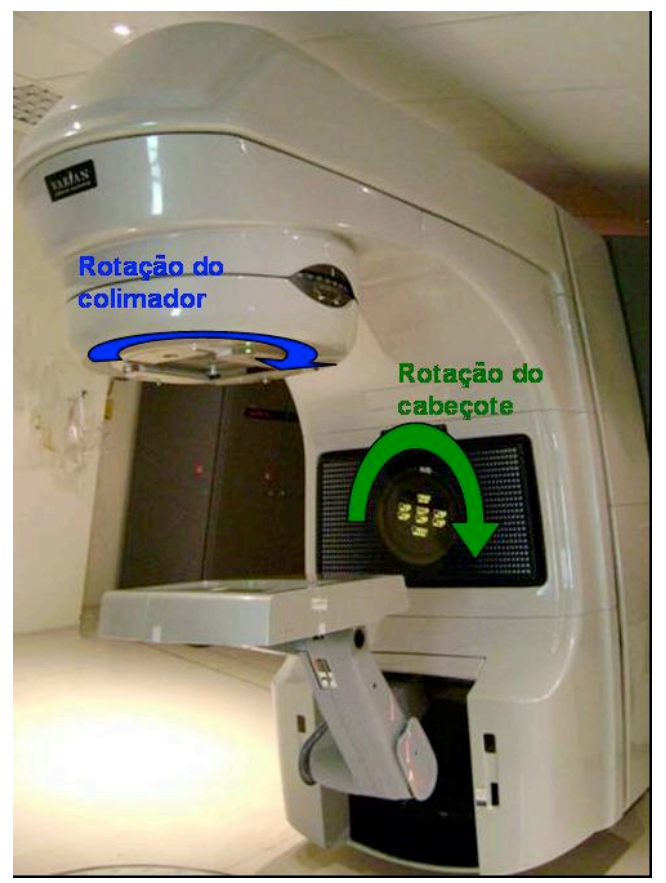

Figura 15: Ilustração da rotação do cabeçote e do colimador.

\subsubsection{Resposta do portal dosimetry em função da distância}

O PD pode ser posicionado em diferentes distâncias para a realização das medidas. Para avaliar se a resposta do PD é diretamente proporcional ao inverso do quadrado da distância utilizou-se um campo $10 \times 10 \mathrm{~cm}^{2}, 100 \mathrm{UM}$ e taxa de dose $=400 \mathrm{UM} / \mathrm{min}$. Os valores foram obtidos posicionando o PD em diferentes 
distancias fonte-superfície: 100, 110, 120, 130 e $140 \mathrm{~cm}$. As distâncias analisadas representam as possíveis distâncias a serem empregadas clinicamente.

\subsubsection{Reprodutibilidade da resposta do portal dosimetry}

A reprodutibilidade é uma das principais características de um detector. A avaliação desse parâmetro foi feita utilizando-se 50 UM, taxa de dose de 400 $\mathrm{UM} / \mathrm{min}$ e SSD $=100 \mathrm{~cm}$. Repetiu-se a aquisição das imagens por dez vezes e, a partir do valor do raio central $(0,0,0)$ obtido, observou-se o desvio padrão entre as medidas.

\subsubsection{Uniformidade da resposta ao longo da área ativa do dispositivo}

Para uma dada fluência homogênea, a resposta dos detectores deve ser a mesma, respeitando-se as características do feixe, em toda a área do dispositivo. Investigou-se a uniformidade utilizando-se um campo de $28 \times 28 \mathrm{~cm}^{2}, 50$ UM e taxa de dose de $400 \mathrm{UM} / \mathrm{min}$. Obteve-se os valores de dose no pontos $\mathrm{P}_{1}, \mathrm{P}_{2}, \mathrm{P}_{3}$, $\mathrm{P}_{4}, \mathrm{P}_{5}, \mathrm{P}_{6}, \mathrm{P}_{7}$ e $\mathrm{P}_{8}$ distribuídos ao longo da área ativa do EPID, ilustrados na Figura 16, e comparou-se com o valor obtido na região central $\mathrm{P}_{0}$.

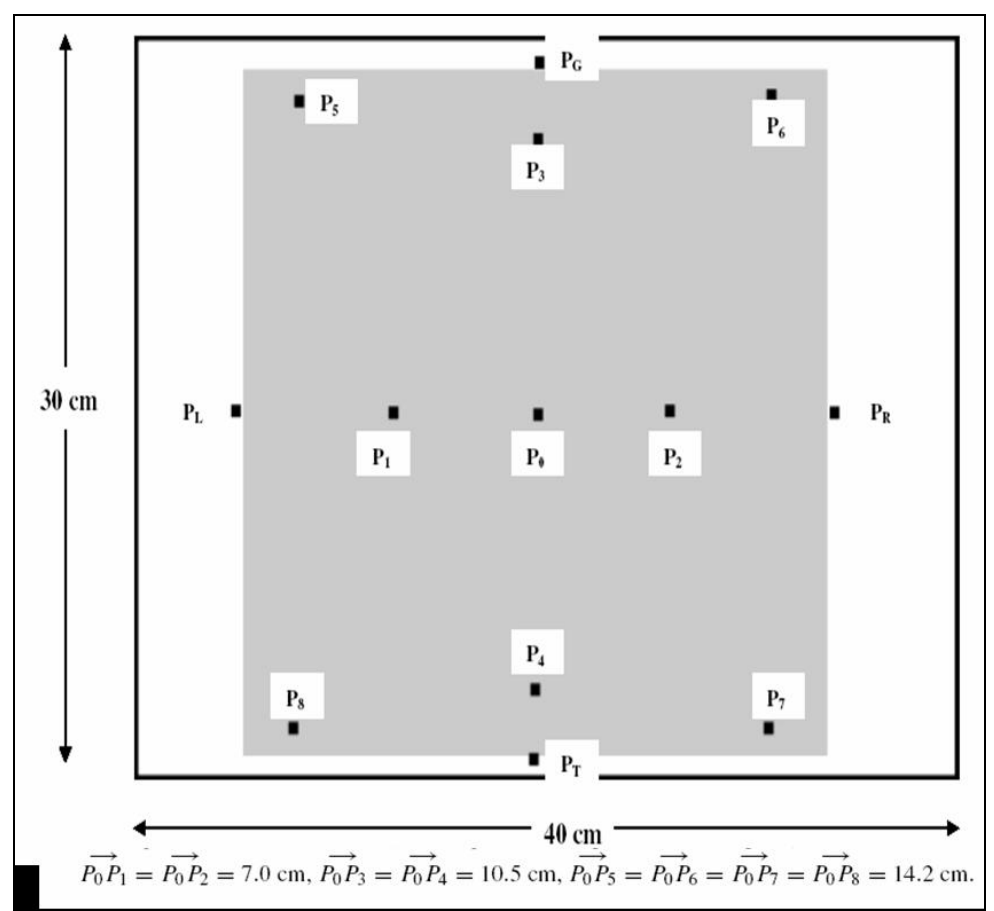

Figura 16: Especificação da localização dos pontos utilizados para medir a uniformidade em um campo de radiação de $28 \times 28 \mathrm{~cm}^{2}$ no EPID. 


\subsubsection{Efeito de memória nos detectores do portal dosimetry}

O PD é uma matriz de detectores semicondutores de silício amorfo e o teste de memória é importante para avaliar se há influência de uma leitura na outra subseqüente. Para avaliar esse efeito obteve-se uma imagem com um campo de $10 \times 10 \mathrm{~cm}^{2}, 500 \mathrm{UM}$, taxa de dose de $400 \mathrm{MU} / \mathrm{min}$ e SSD=100 cm. Em seguida, alterou-se a unidade monitora para $10 \mathrm{MU}$ e obteve-se nova imagem. Por fim, alterou-se o tamanho de campo para $20 \times 20 \mathrm{~cm}^{2}$ e a unidade monitora para 3 UM. A escolha de um valor baixo de UM se deve ao interesse em se avaliar a influência da memória dos detectores em uma baixa dose. As imagens obtidas foram analisadas através da comparação dos perfis de dose de cada uma delas, principalmente na área irradiada comum entre elas.

\subsubsection{Influência da taxa de dose na resposta do portal dosimetry}

A resposta do detector pode variar com a taxa de dose do acelerador linear, porém é desejável que essa variação não exista, já que para um tratamento de radioterapia pode-se utilizar diferentes taxas de dose. As respostas do PD em função da taxa de dose foram obtidas mantendo-se constantes a SSD $=100 \mathrm{~cm}$, 0 campo $10 \times 10 \mathrm{~cm}^{2}$, a unidade monitora = 100UM e variando-se a taxa de dose de 100 a 600MU/min, com incrementos de 100.

\subsection{Avaliação das Fluências}

Após os testes de comissionamento, foram realizados testes com uma fluência conhecida simples para um campo $10 \times 10 \mathrm{~cm}^{2}$ e utilizando-se essa mesma fluência introduziu-se erros determinados a fim de se avaliar a sensibilidade do dispositivo em detectar alterações na fluência em termos de diferença de dose e da área em que essa diferença se apresenta.

Uma fluência simples para um campo $10 \times 10 \mathrm{~cm}^{2}$ foi gerada no sistema de planejamento Eclipse 7.3 - Varian. Em seguida, foram introduzidos erros nessa fluência original de $\pm 3,4,5,6,7$ e $10 \%$ em uma área de $2 \times 2 \mathrm{~cm}^{2}$ e $4 \times 4 \mathrm{~cm}^{2}$ a 
partir do centro do campo. Também foram introduzidos erros de -3, -5 e -7\% em campos fora do centro do campo. Gerou-se os planos de controle de qualidade com o dispositivo portal, com a câmara de ionização, e com o seven29. A introdução desses erros conhecidos foi feita para a avaliação da sensibilidade dos métodos de controle de qualidade na detecção de erros em um plano de dose.

As medidas do controle de qualidade planar foram feitas utilizando-se 0 acelerador linear 21EX da Varian, um objeto simulador de material equivalente a água (RW3), uma câmara de ionização de 0,125cc de volume - TN 31010, um eletrômetro (UNIDOS E), uma matriz de câmaras de ionização contendo 729 câmaras dispostas em um campo $27 \times 27 \mathrm{~cm}^{2}$ (seven29), o dispositivo de dosimetria portal (PD - aSi500II), filmes especiais para doses estendidas (KODAK-EDR2), um scanner (Vidar), o sistema de planejamento de tratamento (Eclipse 7.3) e o software de análise de dados (Verisoft).

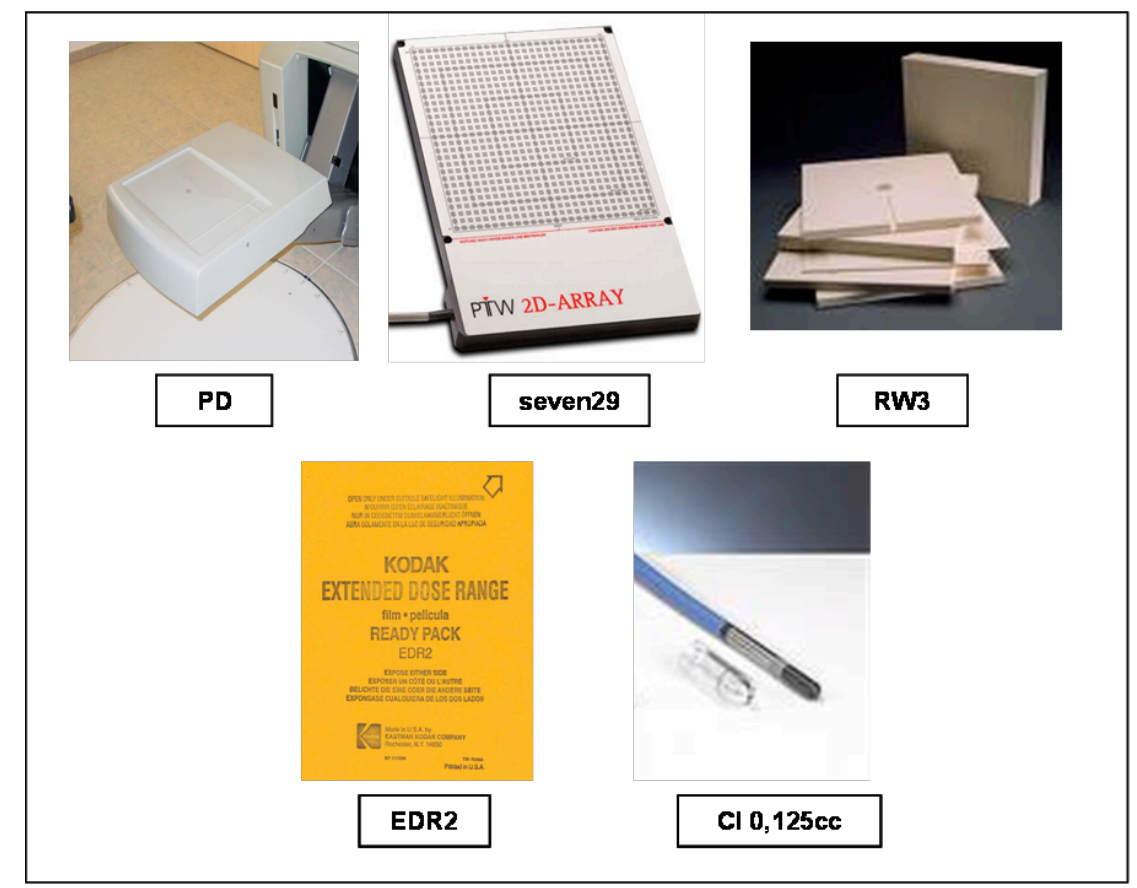

Figura 17: Ilustração do material utilizado - dispositivo portal (PD); matriz de câmaras de ionização (seven29); objeto simulador de material equivalente a água (RW3); filmes especiais para doses estendidas (EDR2); câmara de ionização de $0,125 \mathrm{cc}$ de volume $(\mathrm{Cl} 0,125 \mathrm{cc})$.

A análise dos dados da matriz de câmaras de ionização foi feita no programa Verisoft da PTW através da comparação das fluências modificadas com a original 
em termos de dose no raio central $(R C)$, função gama e perfis. Os dados da câmara de ionização foram analisados comparando-se o valor de dose no raio central das fluências modificadas com a original e a análise dos dados do Portal Dosimetry foi feita no Eclipse - Review - Dosimetry, onde foi feita a comparação das fluências modificadas com a original em termos de dose no raio central, perfis, função gama (gama máximo, gama médio, índice gama e gráfico gama).

Avaliou-se a capacidade do portal dosimetry em identificar os erros propositalmente introduzidos de diferentes magnitudes nas fluências adquiridas, utilizando as próprias ferramentas de análise, comparado com os outros métodos de medidas.

Realizou-se também medidas de fluências complexas utilizadas em um plano de um paciente para tratamento de próstata com cinco campos nos quais foram introduzidos erros variáveis em uma área aproximada de $4,0 \mathrm{~cm}^{2}$ no centro da fluência. Os erros introduzidos foram: campos 1 e $2=+10 \%$, campo $3=-10 \%$, campo $4=-3 \%$ e campo $5=-7 \%$. As medidas das fluências foram feitas com o portal dosimetry e com o seven29 e o valor da dose no raio central foi obtido com a câmara de ionização, com o seven29 e com o portal dosimetry. Essas medidas foram realizadas para verificar se os resultados obtidos com as fluências simples eram aplicáveis também para fluências complexas utilizadas na prática clínica. 


\section{RESULTADOS}

\subsection{Comissionamento}

\subsubsection{Linearidade da leitura com a dose}

A Tabela 1 mostra os valores obtidos com o portal dosimetry, para 6 e 16MV de fótons, em função da unidade monitora (UM), que é o parâmetro selecionado no acelerador linear e que é diretamente proporcional a dose (neste caso, $1 \mathrm{UM}=1 \mathrm{cGy}$ ). As medidas do portal dosimetry são obtidas em unidades de calibração (UC) e 1UC = 1UM conforme a calibração dosimétrica do portal dosimetry. Foi utilizado um campo $10 \times 10 \mathrm{~cm}^{2}$, distância fonte-superfície (SSD) = $100 \mathrm{~cm}$, e taxa de dose $=400 \mathrm{UM} / \mathrm{min}$.

Tabela 1: Linearidade da leitura do portal dosimetry com a unidade monitora (UM) do acelerador linear.

\begin{tabular}{ccc}
\hline UM & $\begin{array}{c}6 \mathrm{MV} \\
\text { Leitura (UC) }\end{array}$ & $\begin{array}{c}16 \mathrm{MV} \\
\text { Leitura (UC) }\end{array}$ \\
\hline 1 & $0,924 \pm 0,007$ & $0,909 \pm 0,008$ \\
2 & $1,886 \pm 0,006$ & $1,851 \pm 0,006$ \\
5 & $4,718 \pm 0,004$ & $4,717 \pm 0,007$ \\
10 & $9,607 \pm 0,003$ & $9,553 \pm 0,004$ \\
20 & $19,463 \pm 0,003$ & $19,478 \pm 0,003$ \\
50 & $49,596 \pm 0,002$ & $49,630 \pm 0,003$ \\
100 & $99,654 \pm 0,004$ & $100,083 \pm 0,002$ \\
200 & $200,008 \pm 0,003$ & $200,720 \pm 0,002$ \\
500 & $500,558 \pm 0,002$ & $502,653 \pm 0,003$ \\
900 & $901,407 \pm 0,001$ & $903,332 \pm 0,002$ \\
\hline
\end{tabular}

A partir desses dados pode-se observar que a resposta do portal dosimetry é diretamente proporcional à unidade monitora. A UM é o parâmetro selecionado no acelerador linear e está diretamente relacionada à dose, pois é realizada uma calibração do aparelho para que essa relação seja verdadeira. Portanto, pode-se 
dizer que a leitura obtida é relacionada linearmente com a dose, assim como era esperado. Na Figura 18 observa-se as equações de ajuste linear dos pontos para 6 e $16 \mathrm{MV}$ e os coeficientes de correlação do ajuste, ambos iguais a 1,0 que indica um ajuste linear perfeito.

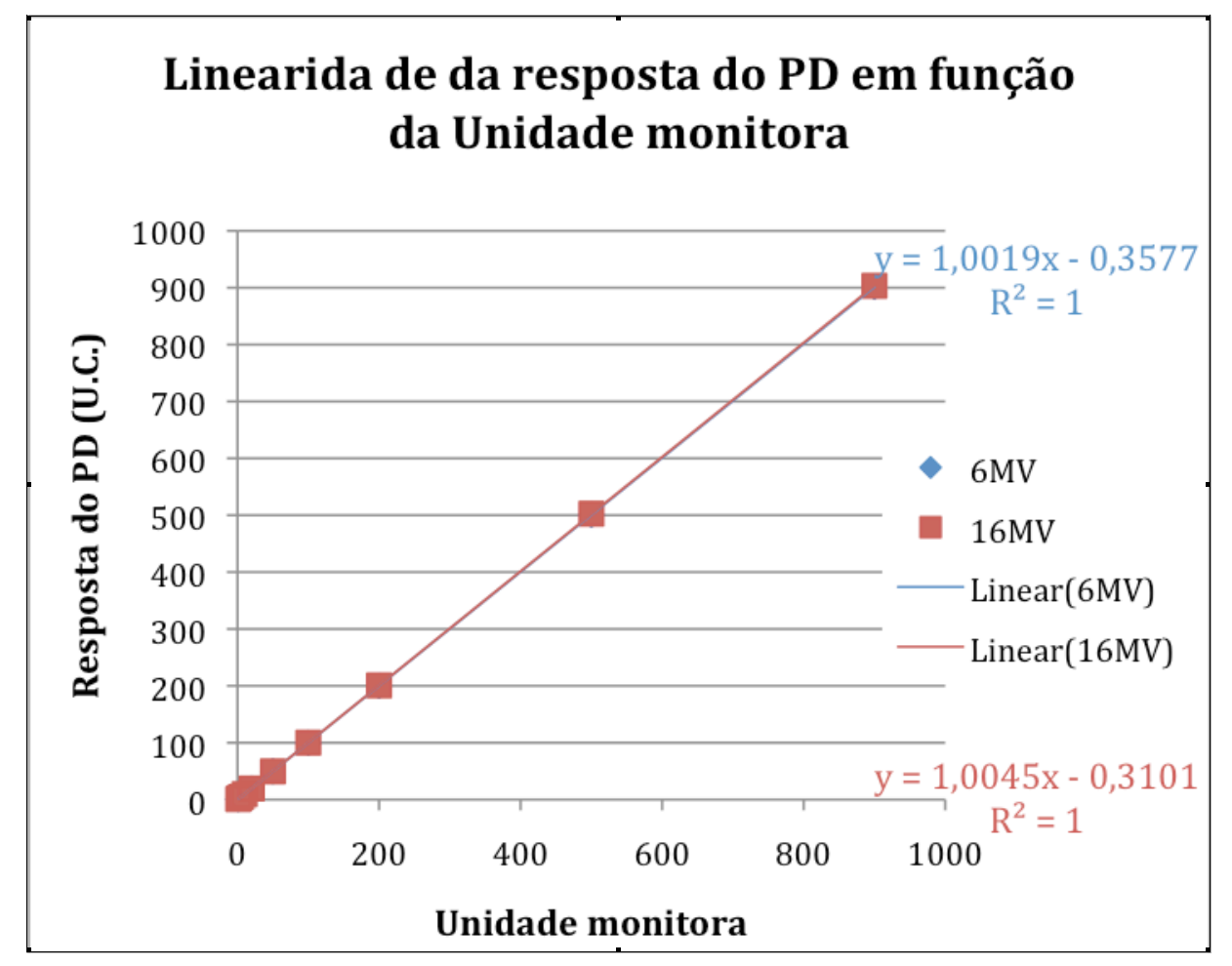

Figura 18: Gráfico da medida obtida com o dosímetro portal em função da unidade monitora do acelerador linear. Os erros foram inseridos, porém são menores que a dimensão dos pontos.

\subsubsection{Dependência direcional}

As medidas obtidas em vários ângulos de cabeçote são apresentadas na Tabela 2. O dosímetro portal tem a capacidade de realizar medidas em diferentes angulações do cabeçote, característica que o diferencia da maioria dos dosímetros equivalentes a ele. Nesse teste o dispositivo de imagem portal foi mantido sempre a $100 \mathrm{~cm}$ de distância fonte-superfície, foi utilizado um campo de 
$10 \times 10 \mathrm{~cm}^{2}, 50 \mathrm{UM}$ e taxa de dose de 400UM/min e o cabeçote foi posicionado em diferentes angulações. Os valores foram normalizados para a leitura obtida com o ângulo zero.

Tabela 2: Efeito da rotação do cabeçote na leitura do portal dosimetry.

\begin{tabular}{ccc}
\hline & $6 \mathrm{MV}$ & $16 \mathrm{MV}$ \\
Ângulo do cabeçote & Leitura (UC) & Leitura (UC) \\
\hline $0^{\circ}$ & 1,000 & 1,000 \\
$15^{\circ}$ & 1,002 & 1,001 \\
$30^{\circ}$ & 1,004 & 1,003 \\
$45^{\circ}$ & 1,005 & 1,003 \\
$60^{\circ}$ & 1,002 & 1,005 \\
$75^{\circ}$ & 1,005 & 1,005 \\
$90^{\circ}$ & 1,003 & 1,006 \\
$105^{\circ}$ & 1,006 & 1,007 \\
$120^{\circ}$ & 1,010 & 1,010 \\
$135^{\circ}$ & 1,011 & 1,011 \\
$150^{\circ}$ & 1,013 & 1,012 \\
$165^{\circ}$ & 1,013 & 1,011 \\
$180^{\circ}$ & 1,012 & 1,012 \\
$195^{\circ}$ & 1,011 & 1,007 \\
$210^{\circ}$ & 1,011 & 1,010 \\
$225^{\circ}$ & 1,012 & 1,009 \\
$240^{\circ}$ & 1,011 & 1,009 \\
$255^{\circ}$ & 1,009 & 1,007 \\
$270^{\circ}$ & 1,008 & 1,008 \\
$285^{\circ}$ & 1,003 & 1,007 \\
$300^{\circ}$ & 1,004 & 1,007 \\
$315^{\circ}$ & 1,003 & 1,004 \\
$330^{\circ}$ & 1,002 & 1,004 \\
$345^{\circ}$ & 1,003 & 1,005 \\
\hline Mínimo & 1,000 & 1,000 \\
Máximo & 1,013 & 1,012 \\
Média $_{\text {Desvio padrão }}$ & 1,007 & 1,007 \\
\hline & 0,004 & 0,003 \\
\hline & & \\
\hline
\end{tabular}

A parte final da Tabela 2 indica os valores mínimos, máximos e médios obtidos e pode-se observar que a leitura é independente do ângulo do cabeçote já que as leituras em diferentes ângulos de cabeçote variaram em até 1,3\% para $6 \mathrm{MV}$ e $1,2 \%$ para $16 \mathrm{MV}$, sendo que as maiores variações, acima de $1,0 \%$, 
ocorrem para ângulos de cabeçote posteriores, de $120^{\circ}$ a $240^{\circ}$. Esses resultados estão de acordo com Kavuma e colaboradores ${ }^{38}$ que indicam variações de até $2 \%$ nos valores encontrados.

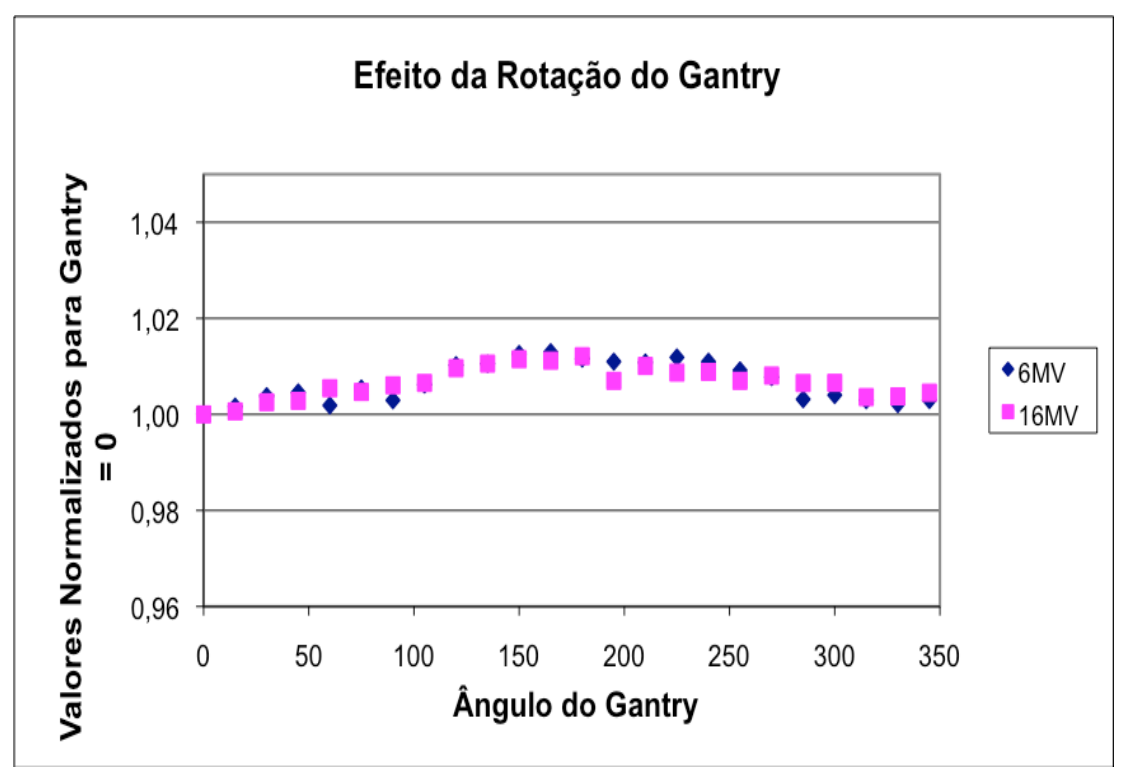

Figura 19: Gráfico das leituras obtidas com o portal dosimetry em função do ângulo do cabeçote. Os erros foram inseridos, porém são menores que a dimensão dos pontos.

A flutuação dos valores de leitura obtidos em função da variação do ângulo do cabeçote está entre 0 e 1,3\% e pode ser mais facilmente observada através do gráfico da Figura 19.

A independência direcional é bastante importante já que a realização do controle de qualidade dos planos de IMRT nos ângulos verdadeiros do plano de tratamento é uma vantagem do portal dosimetry em relação a outros dispositivos utilizados para esse fim e é fundamental que não haja alterações significativas nas leituras em diferentes ângulos de cabeçote.

\subsubsection{Resposta do portal dosimetry em função da distância}

Esse teste foi realizado para avaliar se a resposta do dispositivo é diretamente proporcional ao inverso do quadrado da distância, ou seja, se ele obedece a lei do inverso do quadrado da distância. Utilizou-se um campo 
$10 \times 10 \mathrm{~cm}^{2}, 100 \mathrm{UM}$, taxa de dose $=400 \mathrm{UM} / \mathrm{min}$ e variou-se a distância fontesuperfície (SSD) determinada na superfície do dosímetro portal. Os dados são apresentados na tabela 3 e apresentam um comportamento linear que pode ser melhor visualizado no gráfico da figura 20.

Tabela 3: Leitura do portal dosimetry em função da variação da distância fontesuperficie (SSD).

\begin{tabular}{ccc}
\hline SSD $(\mathrm{cm})$ & $\begin{array}{c}6 \mathrm{MV} \\
\text { Leitura (UC) }\end{array}$ & $\begin{array}{c}\text { LMV } \\
\text { Leitura (UC) }\end{array}$ \\
\hline 100 & $99,972 \pm 0,004$ & $100,058 \pm 0,003$ \\
110 & $82,950 \pm 0,003$ & $82,517 \pm 0,003$ \\
120 & $69,807 \pm 0,004$ & $68,255 \pm 0,002$ \\
130 & $59,354 \pm 0,005$ & $58,904 \pm 0,002$ \\
140 & $51,459 \pm 0,002$ & $50,344 \pm 0,003$ \\
\hline
\end{tabular}

O gráfico da Figura 20, criado a partir dos dados da Tabela 3, indica que as leituras de 6 e 16MV obtidas com o dispositivo seguem a lei do inverso do quadrado da distância conforme o esperado.

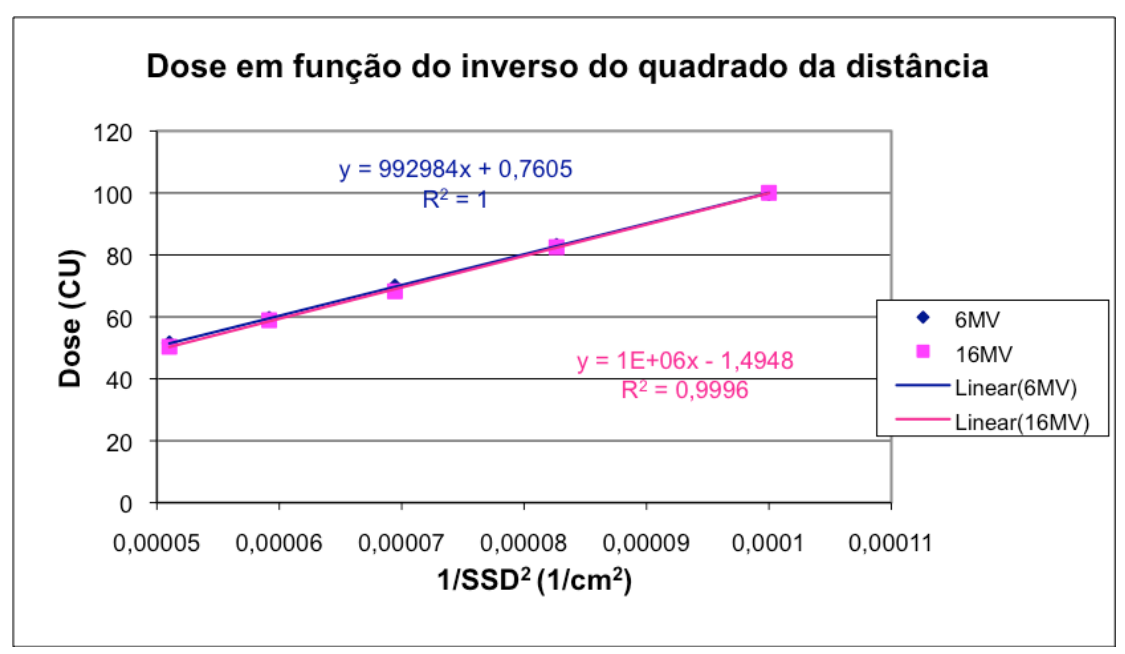

Figura 20: Gráfico da leitura obtida em função do inverso do quadrado da distância. Os erros foram inseridos, porém são menores que a dimensão dos pontos. 


\subsubsection{Reprodutibilidade da resposta do portal dosimetry}

Esse teste foi realizado para avaliar a estabilidade das leituras do portal dosimetry através de várias irradiações utilizando-se as mesmas condições para o feixe: campo de $10 \times 10 \mathrm{~cm}^{2}, 50 \mathrm{UM}$, taxa de dose de $400 \mathrm{UM} / \mathrm{min}$ e SSD $=100 \mathrm{~cm}$. Os resultados estão apresentados na Tabela 4.

Tabela 4: Reprodutibilidade da leitura do portal dosimetry.

\begin{tabular}{ccc}
\hline Medida & GMV & $\begin{array}{c}16 \mathrm{MV} \\
\text { Medida }(\mathrm{UC})\end{array}$ \\
\hline 1 & $49,655 \pm 0,003$ & $48,558 \pm 0,002$ \\
2 & $49,803 \pm 0,002$ & $48,770 \pm 0,002$ \\
3 & $49,856 \pm 0,003$ & $48,785 \pm 0,002$ \\
4 & $49,788 \pm 0,002$ & $48,754 \pm 0,003$ \\
5 & $49,695 \pm 0,003$ & $48,739 \pm 0,001$ \\
6 & $49,761 \pm 0,003$ & $48,800 \pm 0,001$ \\
7 & $49,762 \pm 0,001$ & $48,769 \pm 0,003$ \\
8 & $49,816 \pm 0,001$ & $48,658 \pm 0,003$ \\
9 & $49,642 \pm 0,002$ & $48,329 \pm 0,002$ \\
10 & $49,789 \pm 0,004$ & $48,748 \pm 0,001$ \\
\hline Mínimo & 49,642 & 48,329 \\
Máximo & 49,856 & 48,800 \\
Média & 49,757 & 48,691 \\
Desvio padrão & 0,071 & 0,146 \\
\hline
\end{tabular}

Os valores de desvio padrão obtidos das leituras estão de acordo com o esperado já que os valores obtidos para 6 e $16 \mathrm{MV}(0,07$ e 0,15 respectivamente) são menores do que os desvios publicados por Kavuma e colaboradores ${ }^{38}$, de 0,13 para $6 \mathrm{MV}$ e 0,20 para $16 \mathrm{MV}$, obtidos com dois dispositivos semelhantes em marca e modelo ao dispositivo em estudo neste trabalho. 


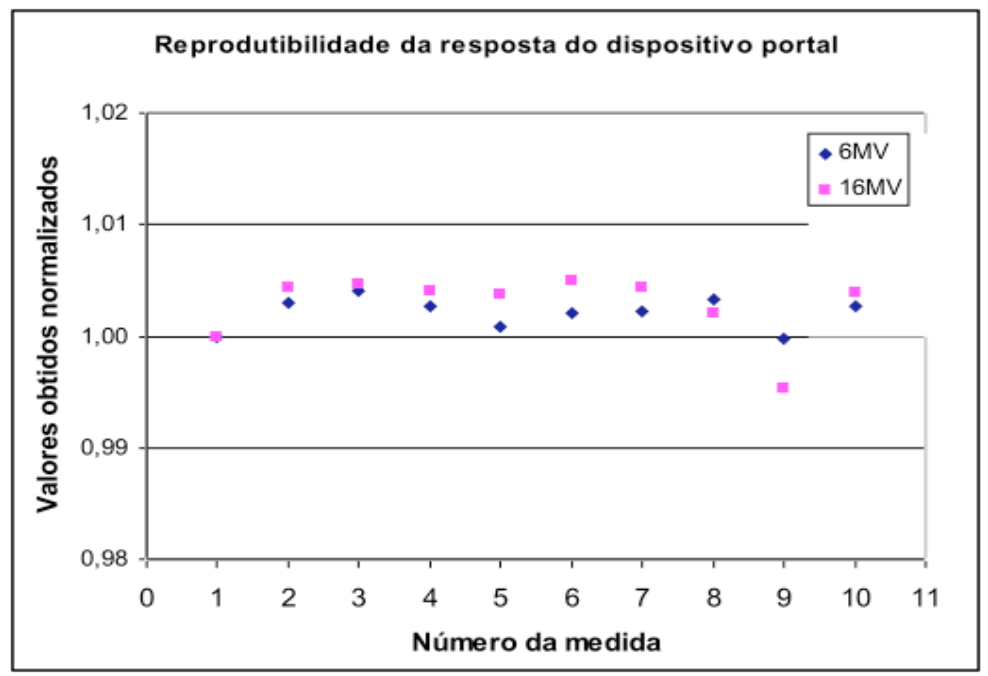

Figura 21: Gráfico da leitura obtida com o portal dosimetry em função do número de medidas. Os erros foram inseridos, porém são menores que a dimensão dos pontos.

Os valores apresentados na Figura 21 indicam a boa reprodutibilidade do dispositivo devido à pequena variação entre as leituras apresentadas, ou seja, menor que $0,5 \%$ para $6 \mathrm{MV}$ e menor que $1,0 \%$ para $16 \mathrm{MV}$.

\subsubsection{Uniformidade da resposta ao longo da área ativa do dispositivo}

O teste de uniformidade da resposta ao longo da área ativa do dispositivo foi realizado com a finalidade de avaliar se a área ativa do detector responde de maneira similar à região central. Para isso, utilizou-se um campo de $28 \times 28 \mathrm{~cm}^{2}$, $50 \mathrm{UM}$, taxa de dose de $400 \mathrm{UM} / \mathrm{min}, \mathrm{SSD}=100 \mathrm{~cm}$ e foram adquiridas medidas de vários pontos (de $\mathrm{P}_{0}$ a $\mathrm{P}_{8}$ ) distribuídos ao longo de toda a área do campo e os valores são mostrados na Tabela 5. 


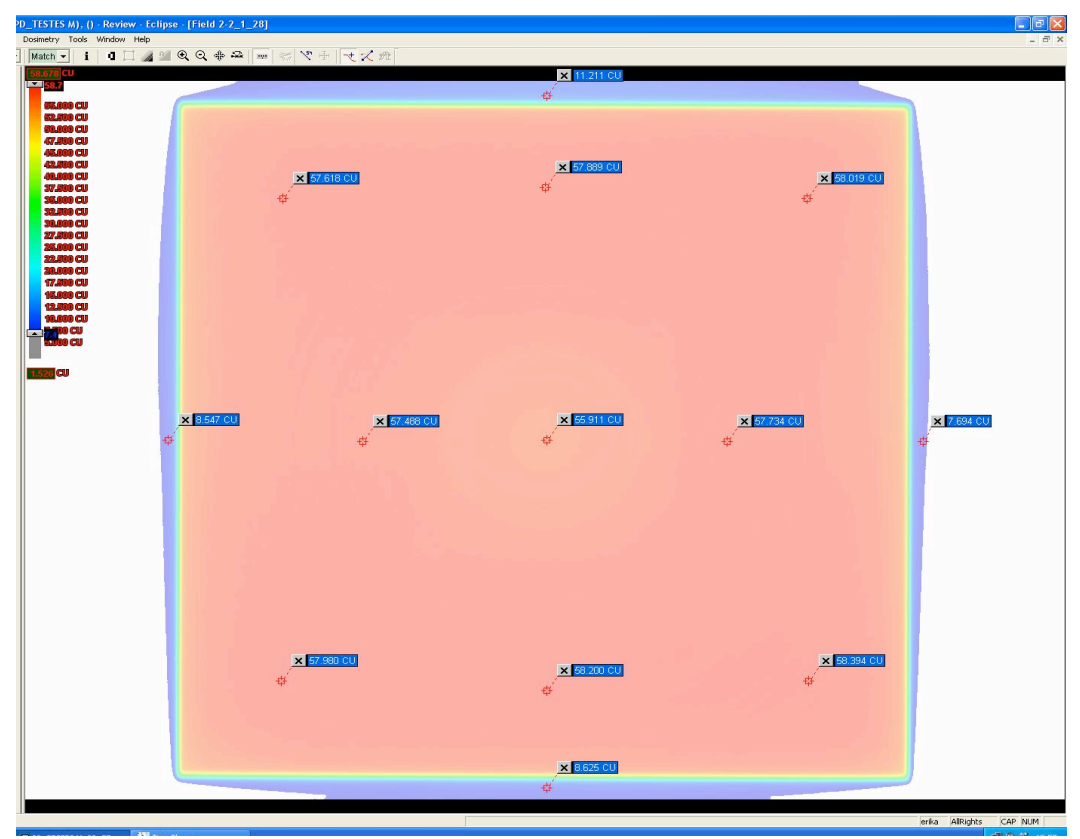

Figura 22: Ilustração das leituras dos pontos $\mathrm{P}_{0}$ a $\mathrm{P}_{8}$ e $\mathrm{P}_{\text {méd, }}$ para $6 \mathrm{MV}$.

A determinação dos pontos foi feita conforme indicado na Figura 16 da seção 4.1.7.

Tabela 5: Uniformidade da leitura na área ativa do portal dosimetry.

\begin{tabular}{ccc}
\hline & $6 \mathrm{MV}$ & $16 \mathrm{MV}$ \\
Pontos & Medida (UC) & Medida (UC) \\
\hline 0 & $55,911 \pm 0,003$ & $56,240 \pm 0,002$ \\
1 & $57,488 \pm 0,003$ & $58,164 \pm 0,003$ \\
2 & $57,734 \pm 0,003$ & $58,439 \pm 0,003$ \\
3 & $57,889 \pm 0,002$ & $58,652 \pm 0,002$ \\
4 & $58,200 \pm 0,003$ & $58,988 \pm 0,002$ \\
5 & $57,618 \pm 0,004$ & $58,576 \pm 0,005$ \\
6 & $58,019 \pm 0,004$ & $59,003 \pm 0,004$ \\
7 & $57,980 \pm 0,004$ & $59,324 \pm 0,004$ \\
8 & $58,394 \pm 0,004$ & $58,912 \pm 0,004$ \\
$P_{\text {méd }}$ & $9,019 \pm 0,010$ & $9,728 \pm 0,009$ \\
\hline Mínimo & 54,01 & 53,01 \\
Máximo & 55,30 & 54,86 \\
Média & 54,57 & 53,91 \\
\hline
\end{tabular}


A Tabela 6 indica a comparação dos valores obtidos, normalizados para o ponto $\mathrm{P}_{0}$, com os valores publicados por Kavuma e colaboradores ${ }^{38}$ para 6MV. Essa comparação indica que as leituras obtidas diferem em até 8,3\% dos dados da literatura para um acelerador linear de mesmo modelo no utilizado nessas medidas. Essa diferença pode ocorrer devido as características intrínsecas de cada feixe tais como a planura que é diretamente dependente do filtro aplainador presente em cada equipamento, ou seja, mesmo sendo aparelhos da mesma marca e modelo eles podem apresentar diferenças dosimétricas no feixe de radiação. Além disso, deve se considerar também a possibilidade de pequenas diferenças nas respostas dos conjuntos de detectores semicondutores em um dispositivo portal em relação ao outro. Convém citar que as respostas do dispositivo portal estão diretamente condicionadas a calibração efetiva e periódica de toda a área do detector.

Tabela 6: Comparação dos valores obtidos, normalizados para o valor de $\mathrm{P}_{0}$, com os dados de Kavuma e colaboradores ${ }^{38}$

\begin{tabular}{cccc}
\hline & \multicolumn{3}{c}{ Fótons -6MV } \\
\hline Pontos & Medido & Literatura & Diferença \\
\hline $\mathrm{P}_{1}$ & 1,028 & 0,998 & $2,9 \%$ \\
$\mathrm{P}_{2}$ & 1,033 & 0,994 & $3,8 \%$ \\
$\mathrm{P}_{3}$ & 1,035 & 0,987 & $4,6 \%$ \\
$\mathrm{P}_{4}$ & 1,041 & 0,997 & $4,2 \%$ \\
$\mathrm{P}_{5}$ & 1,031 & 0,959 & $7,0 \%$ \\
$\mathrm{P}_{6}$ & 1,038 & 0,957 & $7,8 \%$ \\
$\mathrm{P}_{7}$ & 1,037 & 0,967 & $6,8 \%$ \\
$\mathrm{P}_{8}$ & 1,044 & 0,957 & $8,3 \%$ \\
$\mathrm{P}_{\mathrm{avr}}$ & 0,161 & 0,164 & $-1,9 \%$ \\
\hline
\end{tabular}

Portanto pode se considerar que a uniformidade da resposta do PORTAL DOSIMETRY é satisfatória já que os pontos distribuídos ao longo da área do campo em questão apresentam uma variação de dose de até $8,3 \%$ devido às 
características dos perfis de dose axial e longitudinal dos diferentes feixes de radiação.

\subsubsection{Efeito de memória nos detectores do portal dosimetry}

O teste de memória dos detectores do portal dosimetry tem o objetivo de avaliar a influência de medidas anteriores nas medidas sucessivas. A Tabela 7 apresenta as leituras adquiridas para doses baixas medidas seguidamente a uma dose bastante alta, comparativamente.

Tabela 7: Efeito de memória dos detectores do portal dosimetry.

\begin{tabular}{cccc}
\hline & & $6 \mathrm{MV}$ & $16 \mathrm{MV}$ \\
Campo $\left(\mathrm{cm}^{2}\right)$ & U.M. & Valor medido (UC) & Valor medido (UC) \\
\hline $10 \times 10$ & 500 & $504,885 \pm 0,001$ & $493,624 \pm 0,005$ \\
$10 \times 10$ & 10 & $9,632 \pm 0,007$ & $9,336 \pm 0,008$ \\
$20 \times 20$ & 3 & $3,037 \pm 0,009$ & $3,012 \pm 0,010$ \\
\hline
\end{tabular}

Pode-se notar que não há influência do efeito de memória nas leituras realizadas para doses baixas de 3 e 10UM, já que os valores obtidos não apresentaram diferenças significativas entre os valores nominais e dos valores obtidos no teste de linearidade apresentado na Tabela 7.

\subsubsection{Influência da taxa de dose na resposta do portal dosimetry}

A avaliação da influência da taxa de dose na leitura do portal dosimetry foi realizada mantendo-se constantes a SSD $=100 \mathrm{~cm}$, o campo $10 \times 10 \mathrm{~cm}^{2}, 100 \mathrm{UM} \mathrm{e}$ variando-se a taxa de dose de $100 \mathrm{UM} / \mathrm{min}$ a $600 \mathrm{Um} / \mathrm{min}$ em incrementos de 100. Os valores são apresentados na Tabela 8. 
Tabela 8: Leitura do portal dosimetry, no raio central, em função da variação da taxa de dose.

\begin{tabular}{ccc}
\hline $\begin{array}{c}\text { Taxa de dose } \\
(\text { UM/min })\end{array}$ & Medida (UC) & Medida (UC) \\
\hline 100 & $99,731 \pm 0,004$ & $99,654 \pm 0,003$ \\
200 & $99,874 \pm 0,003$ & $99,604 \pm 0,003$ \\
300 & $99,364 \pm 0,002$ & $99,762 \pm 0,004$ \\
400 & $99,640 \pm 0,001$ & $99,695 \pm 0,003$ \\
500 & $99,862 \pm 0,002$ & $99,685 \pm 0,001$ \\
600 & $99,751 \pm 0,002$ & $99,711 \pm 0,001$ \\
\hline
\end{tabular}

A figura 23 apresenta o gráfico da resposta do PD em função da taxa de dose normalizada para o valor de $400 \mathrm{UM} / \mathrm{min}$.

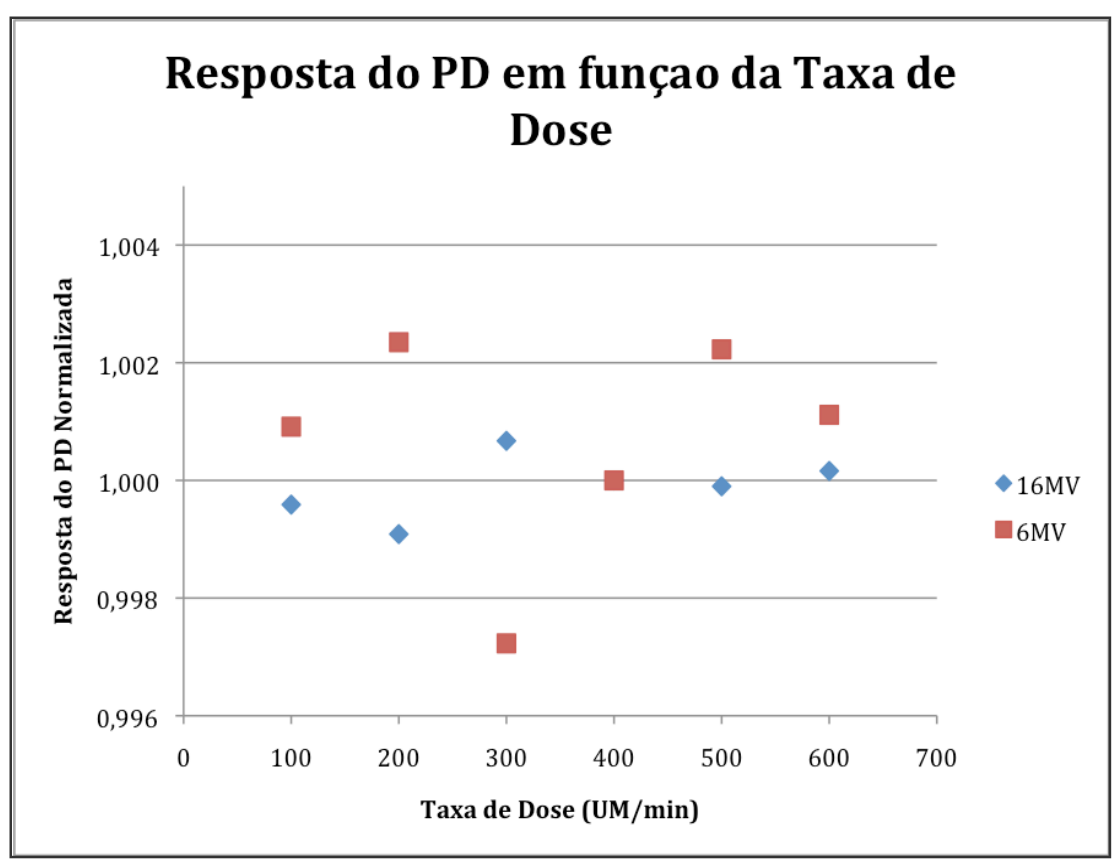

Figura 23: Gráfico da resposta do portal dosimetry em função da taxa de dose. Os erros foram inseridos, porém são menores que a dimensão dos pontos. 
A Figura 23 indica que as variações obtidas entre as leituras são menores do que $0,5 \%$. Por essa razão pode-se afirmar que resposta do portal dosimetry é, portanto independente da taxa de dose

\subsection{Avaliação das Fluências}

\subsubsection{Fluências simples}

A avaliação da capacidade de identificação de erros nas fluências foi realizada utilizando uma fluência simples na qual foram introduzidas variações de dose de $\pm 3,4,5,6,7$ e $10 \%$ em uma área de $2 \times 2 \mathrm{~cm}^{2}$ e $4 \times 4 \mathrm{~cm}^{2}$ a partir do centro do campo da fluência original. As leituras obtidas no raio central são apresentadas nas tabelas IX e X. Devido aos diferentes tipos de respostas (unidades) obtidas com cada dispositivo, os valores de cada um deles foram normalizados para seus respectivos valores obtidos para a fluência original.

A avaliação dos dados utilizando o PORTAL DOSIMETRY pode ser feita através de parâmetros quantitativos da função gama como o valor gama máximo e médio, índice gama, ou de parâmetros qualitativos com o a análise visual da área do gráfico gama maior do que 1,0 e a comparação também visual dos perfis de dose traçados na fluência em questão.

Na tabela 9 observa-se que os valores obtidos com a câmara de ionização, o seven29 e com o portal dosimetry são equivalentes. Já os valores obtidos com os filmes diferem dos demais. Todas as medidas foram feitas a partir de um mesmo plano gerado no sistema de planejamento e utilizando-se o mesmo setup experimental e por essa razão esperava-se que todos os valores obtidos com os diferentes tipos de detectores fossem iguais. As diferenças observadas nas medidas com os filmes podem ser atribuídas ao processo de revelação do filme ou ao processo de digitalização que podem influenciar diretamente nas leituras obtidas. 
Tabela 9: Comparação das medidas, normalizadas para o valor da fluência original, obtidas com $\mathrm{Cl}$, seven29, filme e portal dosimetry.

\begin{tabular}{cccccccccc}
\hline \multicolumn{1}{c}{} & \multicolumn{1}{c}{$6 \mathrm{MV}$} & & & \multicolumn{3}{c}{$16 \mathrm{MV}$} \\
Variação & $\begin{array}{c}\text { Área } \\
\left(\mathrm{cm}^{2}\right)\end{array}$ & $\mathrm{Cl}$ & 729 & $\mathrm{PD}$ & Filme & $\mathrm{Cl}$ & 729 & $\mathrm{PD}$ & Filme \\
\hline$+3 \%$ & $2 \times 2$ & 1,02 & 1,02 & 1,03 & 1,01 & 1,03 & 1,03 & 1,03 & 1,04 \\
$+3 \%$ & $4 \times 4$ & 1,03 & 1,03 & 1,03 & 1,02 & 1,03 & 1,03 & 1,03 & 1,02 \\
$+4 \%$ & $2 \times 2$ & 1,04 & 1,04 & 1,04 & 1,03 & 1,04 & 1,04 & 1,04 & 1,05 \\
$+4 \%$ & $4 \times 4$ & 1,04 & 1,04 & 1,04 & 1,03 & 1,04 & 1,04 & 1,04 & 1,03 \\
$+5 \%$ & $2 \times 2$ & 1,04 & 1,04 & 1,04 & 1,04 & 1,05 & 1,05 & 1,05 & 1,05 \\
$+5 \%$ & $4 \times 4$ & 1,05 & 1,05 & 1,05 & 1,04 & 1,05 & 1,05 & 1,05 & 1,04 \\
$+6 \%$ & $2 \times 2$ & 1,05 & 1,05 & 1,05 & 1,05 & 1,06 & 1,06 & 1,06 & 1,06 \\
$+6 \%$ & $4 \times 4$ & 1,06 & 1,06 & 1,06 & 1,05 & 1,06 & 1,06 & 1,06 & 1,05 \\
$+7 \%$ & $2 \times 2$ & 1,06 & 1,06 & 1,06 & 1,06 & 1,07 & 1,07 & 1,07 & 1,06 \\
$+7 \%$ & $4 \times 4$ & 1,07 & 1,07 & 1,07 & 1,06 & 1,07 & 1,07 & 1,07 & 1,08 \\
$+10 \%$ & $2 \times 2$ & 1,09 & 1,09 & 1,09 & 1,08 & 1,10 & 1,10 & 1,10 & 1,09 \\
$+10 \%$ & $4 \times 4$ & 1,10 & 1,10 & 1,10 & 1,09 & 1,10 & 1,10 & 1,10 & 1,09 \\
\hline$-3 \%$ & $2 \times 2$ & 0,98 & 0,98 & 0,98 & - & 0,97 & 0,97 & 0,97 & - \\
$-3 \%$ & $4 \times 4$ & 0,98 & 0,98 & 0,98 & - & 0,97 & 0,97 & 0,97 & - \\
$-4 \%$ & $2 \times 2$ & 0,96 & 0,96 & 0,96 & - & 0,96 & 0,96 & 0,96 & - \\
$-4 \%$ & $4 \times 4$ & 0,96 & 0,96 & 0,96 & - & 0,96 & 0,96 & 0,96 & - \\
$-5 \%$ & $2 \times 2$ & 0,95 & 0,95 & 0,95 & - & 0,95 & 0,95 & 0,95 & - \\
$-5 \%$ & $4 \times 4$ & 0,95 & 0,95 & 0,95 & - & 0,95 & 0,95 & 0,95 & - \\
$-6 \%$ & $2 \times 2$ & 0,94 & 0,94 & 0,94 & - & 0,94 & 0,94 & 0,94 & - \\
$-6 \%$ & $4 \times 4$ & 0,94 & 0,94 & 0,94 & - & 0,94 & 0,94 & 0,94 & - \\
$-7 \%$ & $2 \times 2$ & 0,93 & 0,93 & 0,93 & - & 0,93 & 0,93 & 0,93 & - \\
$-7 \%$ & $4 \times 4$ & 0,93 & 0,93 & 0,93 & - & 0,93 & 0,93 & 0,93 & - \\
$-10 \%$ & $2 \times 2$ & 0,90 & 0,90 & 0,90 & - & 0,90 & 0,90 & 0,90 & - \\
$-10 \%$ & $4 \times 4$ & 0,90 & 0,90 & 0,90 & - & 0,90 & 0,90 & 0,90 & - \\
Original & - & 1,00 & 1,00 & 1,00 & 1,00 & 1,00 & 1,00 & 1,00 & 1,00 \\
\hline & & & & & & & & & \\
\hline
\end{tabular}

Observando-se os gráficos da Figura 24, pode-se afirmar que as diferenças apresentadas pelo filme em relação ao outros sistemas dosimétricos não segue nenhuma regra geral e que o dosímetro portal, além de se mostrar equivalente a camara de ionizaçao e ao seven29, apresentou também os resultados mais próximos do esperado quando comparado aos outros sistemas. 

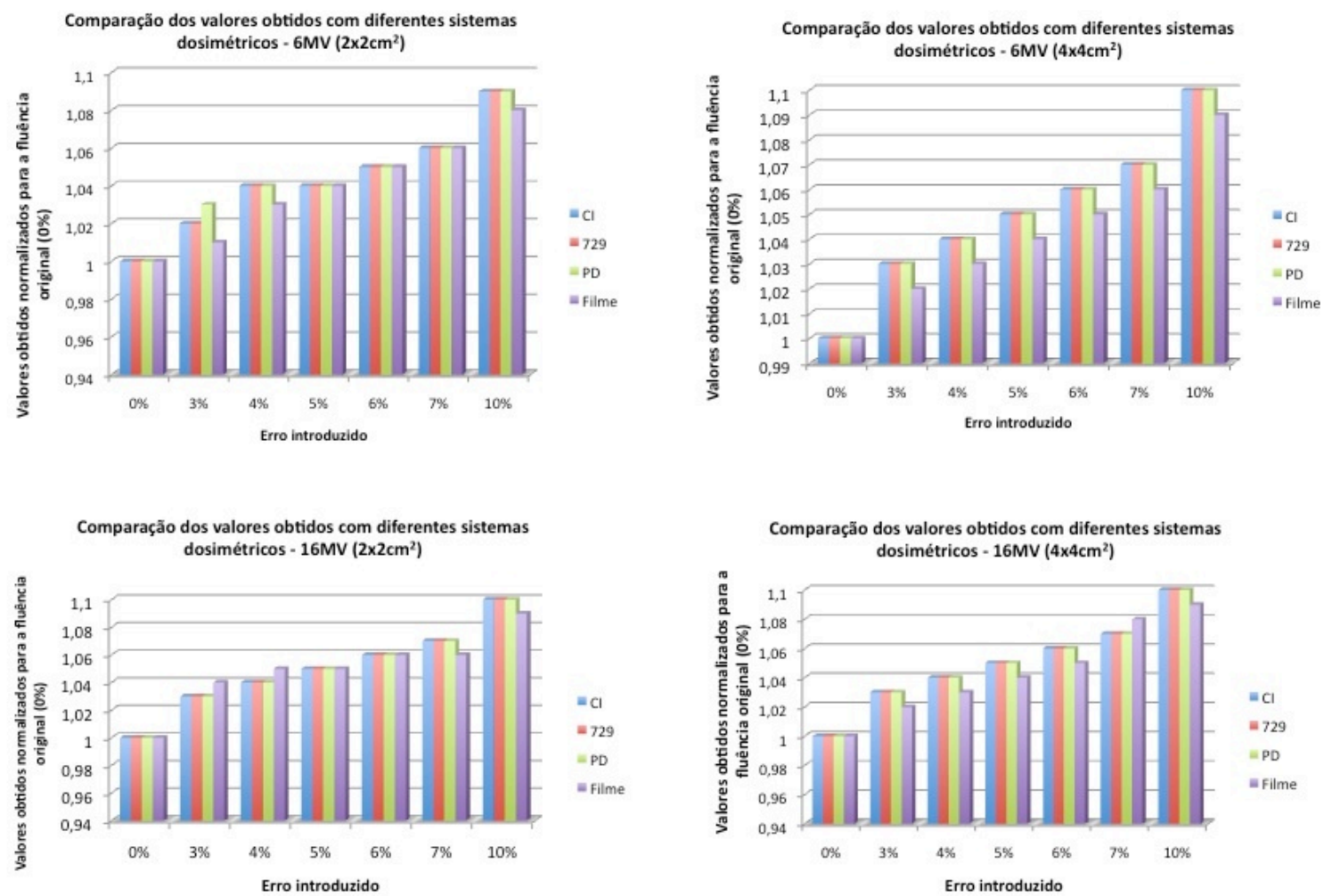

Figura 24: Gráficos das comparações dos valores obtidos com diferentes sistemas dosimétricos para 6 e $16 \mathrm{MV}$ e áreas de $2 \times 2 \mathrm{~cm}^{2}$ e $4 \times 4 \mathrm{~cm}^{2}$ nas quais os erros foram introduzidos.

As fluências medidas com o portal dosimetry foram avaliadas em termos quantitativos utilizando-se os índices fornecidos pelo próprio software a partir da análise gama. Na Tabela 10 são apresentados os valores medidos, o índice gama, o gama máximo e o gama médio para os diferentes erros induzidos.

Esperava-se que quanto maior fosse o valor do erro introduzido na fluência e maior fosse a área desse erro maior seria o gama máximo e menor seria o índice gama. Em relação ao gama máximo pode-se observar que o valor de gama máximo aumenta com o aumento da variação de dose e da área em que ela se apresenta, porém para a energia de $16 \mathrm{MV}$, a fluência na qual foi introduzida um erro de $+3 \%$ apresentou um gama máximo maior do que a fluência na qual foi introduzida um erro de $+10 \%$. Isso ocorreu porque em um determinado ponto da fluência medida houve uma diferença grande quando comparada a fluência original, ou seja, esse valor representa apenas um ponto e por essa razão a 
interpretação do gama máximo tem que ser feita com cuidado no contexto da análise do controle de qualidade.

Tabela 10: Variação dos parâmetros quantitativos na análise do PORTAL DOSIMETRY.

\begin{tabular}{|c|c|c|c|c|c|c|c|c|c|}
\hline \multicolumn{6}{|c|}{$6 \mathrm{MV}$} & \multicolumn{4}{|c|}{$16 \mathrm{MV}$} \\
\hline $\begin{array}{c}\text { Variaçã } \\
0\end{array}$ & $\begin{array}{l}\text { Área } \\
\left(\mathrm{cm}^{2}\right)\end{array}$ & $\begin{array}{c}\text { Medido } \\
\text { (CU) }\end{array}$ & $\begin{array}{l}\text { Índice } \\
\text { gama }\end{array}$ & $\begin{array}{l}\text { Gama } \\
\text { máximo }\end{array}$ & $\begin{array}{l}\text { Gama } \\
\text { médio }\end{array}$ & $\begin{array}{c}\text { Medido } \\
\text { (CU) }\end{array}$ & $\begin{array}{l}\text { Índice } \\
\text { gama }\end{array}$ & & $\begin{array}{l}\text { Gama } \\
\text { médio }\end{array}$ \\
\hline Original & - & 68,799 & - & - & - & 63,127 & - & - & - \\
\hline $10 \%$ & $2 \times 2$ & 74,901 & 0,997 & 2,950 & 0,024 & 68,677 & 0,997 & 1,814 & 0,031 \\
\hline $10 \%$ & $4 \times 4$ & 75,416 & 0,986 & 3,250 & 0,062 & 68,977 & 0,987 & 2,246 & 0,035 \\
\hline $7 \%$ & $2 \times 2$ & 73,232 & 0,997 & 2,200 & 0,013 & 66,557 & 0,997 & 1,807 & 0,012 \\
\hline $7 \%$ & $4 \times 4$ & 73,490 & 0,987 & 2,290 & 0,034 & 67,325 & 0,988 & 1,574 & 0,040 \\
\hline $6 \%$ & $2 \times 2$ & 72,217 & 0,997 & 1,660 & 0,017 & 66,591 & 0,990 & 1,057 & 0,406 \\
\hline $6 \%$ & $4 \times 4$ & 72,596 & 0,988 & 1,870 & 0,031 & 66,101 & 0,988 & 1,659 & 0,027 \\
\hline $5 \%$ & $2 \times 2$ & 71,715 & 0,997 & 1,590 & 0,020 & 65,165 & 1,000 & 0,928 & 0,030 \\
\hline $5 \%$ & $4 \times 4$ & 71,867 & 0,999 & 1,600 & 0,033 & 66,256 & 0,989 & 1,289 & 0,023 \\
\hline $4 \%$ & $2 \times 2$ & 71,400 & 0,998 & 1,310 & 0,018 & 64,754 & 1,000 & 0,911 & 0,007 \\
\hline $4 \%$ & $4 \times 4$ & 71,517 & 0,989 & 1,390 & 0,031 & 65,591 & 1,000 & 0,876 & 0,023 \\
\hline $3 \%$ & $2 \times 2$ & 70,583 & 1,000 & 0,940 & 0,017 & 64,865 & 0,997 & 2,836 & 0,018 \\
\hline $3 \%$ & $4 \times 4$ & 70,657 & 0,999 & 1,000 & 0,017 & 64,671 & 0,987 & 3,035 & 0,046 \\
\hline$-3 \%$ & $2 \times 2$ & 59,618 & 1,000 & 0,582 & 0,012 & 56,804 & 0,998 & 1,101 & 0,050 \\
\hline$-3 \%$ & $4 \times 4$ & 59,659 & 1,000 & 0,781 & 0,029 & 56,900 & 0,999 & 1,018 & 0,044 \\
\hline$-4 \%$ & $2 \times 2$ & 59,064 & 1,000 & 0,727 & 0,026 & 56,663 & 0,998 & 1,154 & 0,037 \\
\hline$-4 \%$ & $4 \times 4$ & 58,996 & 1,000 & 0,839 & 0,032 & 56,456 & 0,988 & 1,300 & 0,047 \\
\hline$-5 \%$ & $2 \times 2$ & 58,743 & 1,000 & 0,910 & 0,037 & 56,246 & 0,997 & 1,410 & 0,035 \\
\hline$-5 \%$ & $4 \times 4$ & 58,221 & 0,990 & 1,230 & 0,030 & 55,962 & 0,987 & 1,640 & 0,053 \\
\hline$-6 \%$ & $2 \times 2$ & 57,900 & 0,997 & 1,380 & 0,022 & 55,697 & 0,997 & 1,720 & 0,036 \\
\hline$-6 \%$ & $4 \times 4$ & 57,967 & 0,988 & 1,370 & 0,043 & 55,414 & 0,986 & 1,930 & 0,056 \\
\hline$-7 \%$ & $2 \times 2$ & 57,239 & 0,997 & 1,640 & 0,025 & 54,896 & 0,996 & 2,150 & 0,049 \\
\hline$-7 \%$ & $4 \times 4$ & 57,125 & 0,987 & 1,830 & 0,039 & 54,650 & 0,986 & 2,240 & 0,060 \\
\hline$-10 \%$ & $2 \times 2$ & 56,156 & 0,997 & 2,220 & 0,055 & 53,421 & 0,996 & 2,870 & 0,040 \\
\hline$-10 \%$ & $4 \times 4$ & 55,535 & 0,986 & 2,631 & 0,060 & 52,726 & 0,984 & 3,390 & 0,091 \\
\hline
\end{tabular}


O gama médio aumenta de um modo geral, mas não apresenta um comportamento bem definido.

Os índices gama apresentam comportamento indefinido já que mesmo para um erro de $10 \%$, considerado grande para radioterapia, o índice gama obtido foi de 0,986 para $6 \mathrm{MV}$ e 0,984 para $16 \mathrm{MV}$ que é muito próximo do valor ideal de 1,000. Isso ocorre porque o software que faz a análise dos dados leva em consideração toda a área do dispositivo $\left(30 \times 40 \mathrm{~cm}^{2}\right)$ mesmo que a área irradiada seja apenas de $10 \times 10 \mathrm{~cm}^{2}$. Por essa razão muitos pontos (os pontos não irradiados) apresentam uma dose muito próxima do esperado, influenciando assim no índice gama e fazendo com que ele continue próximo de 1,0 mesmo com grandes alterações na fluência medida. Seria necessário selecionar uma região de interesse para a análise, porem essa ferramenta não está disponível na versão do software utilizada (Eclipse-7.3). Portanto pode-se afirmar que não é possível avaliar um controle de qualidade apenas pelo índice gama.

Devido ao fato de que os índices fornecidos pelo software para análise quantitativa do controle de qualidade de IMRT com o PORTAL DOSIMETRY nem sempre indicam variações importantes de dose na fluência, fez-se necessário analisar os perfis e o gráfico de área gama das fluências.

Além da análise quantitativa das fluências, foi realizada uma análise qualitativa baseada na identificação visual dos erros introduzidos. Na Figura 25 observam-se as fluências original e modificada obtidas com o portal dosimetry.

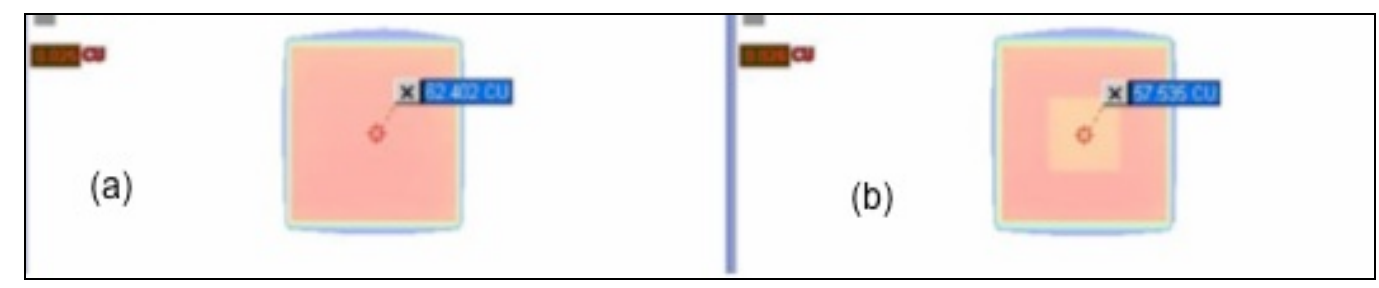

Figura 25: Ilustração das fluências obtidas; (a) original; (b) com -10\% de erro introduzido.

A percepção visual das diferenças nas fluências é bastante evidente pois as imagens possuem uma escala de cor compreendida entre o azul, menor dose, e o 
vermelho, maior dose. Portanto, áreas com doses mais altas apresentam um tom mais forte de vermelho, enquanto que áreas com doses menores apresentam um tom laranja.

Essa diferença nos valores de dose também é perceptível nos filmes utilizados, porém as imagens obtidas possuem uma escala de tons de cinza ao invés de cores como nos dispositivos eletrônicos (portal dosimetry e seven29). $\mathrm{Na}$ Figura 26 observa-se essas diferenças nos diferentes áreas nas quais foram introduzidos erros de $+10 \%$, para o filme e para o portal dosimetry.

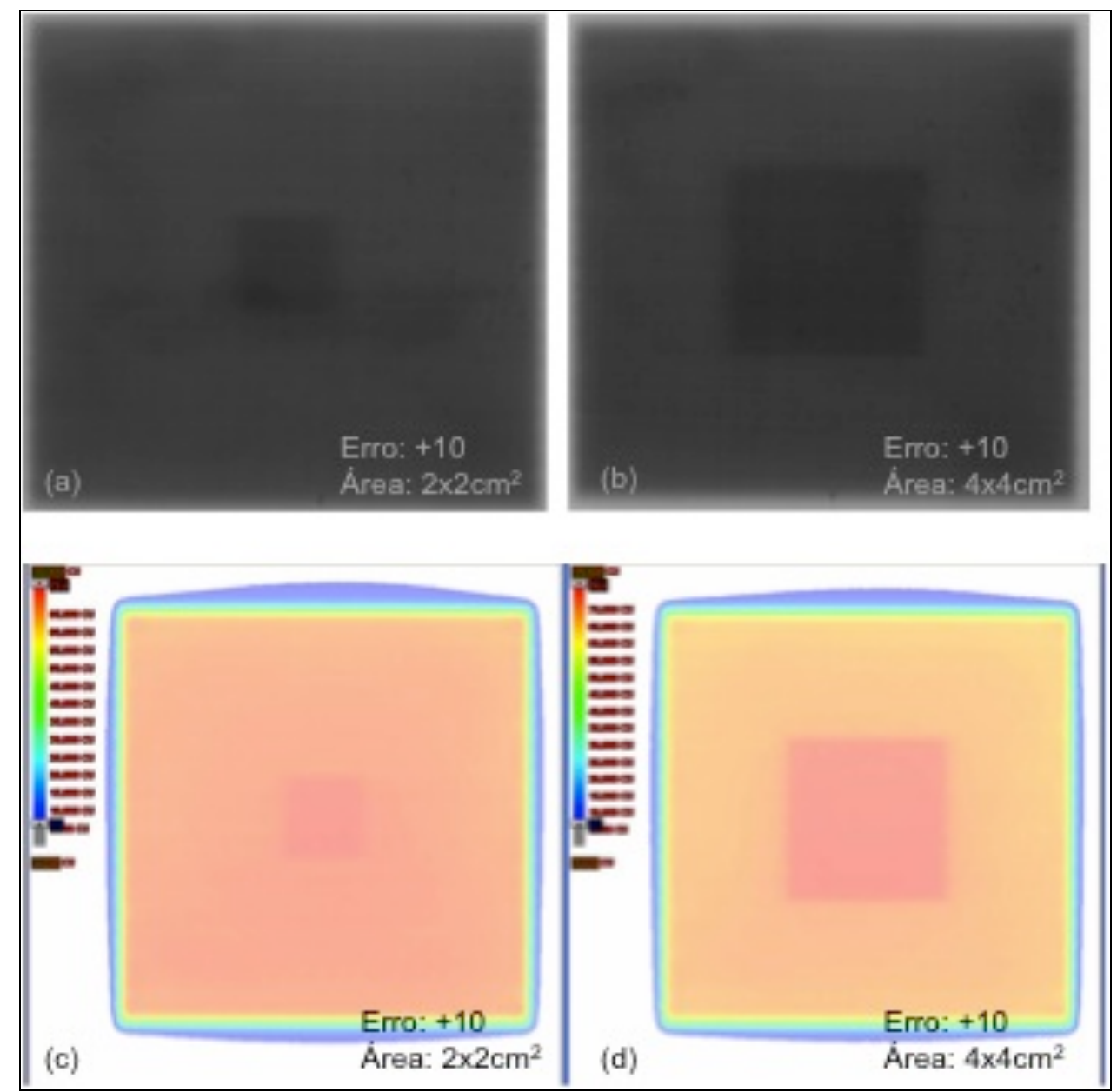

Figura 26: llustração das fluências nas quais foram introduzidas erros de $+10 \%$ em áreas de $2 \times 2 \mathrm{~cm}^{2}$ e $4 \times 4 \mathrm{~cm}^{2}$ para (a) filme e (b) portal dosimetry. 
Além da análise das fluências independentes, realizou-se uma análise qualitativa da função gama aplicada entre a fluência original e as fluências com erros. Essa análise foi realizada no módulo de dosimetria do sistema de revisão de imagens do sistema de planejamento (Eclipse- Review-Dosimetry), no qual se determina um critério de aceitação para a diferença de dose e para a distância de concordância (DTA) conforme descrito na seção 1.2.3. Para esse trabalho foi utilizado o critério de $3 \%$ e $3 \mathrm{~mm}$ e a razão da escolha desses valores foi a relevância para a prática clínica. A figura 27 ilustra a análise gama sendo que, à esquerda estão as duas fluências a serem comparadas e à direita, tem-se o resultado da função gama em termos gráficos e quantitativos (gama máximo, gama médio e índice gama).

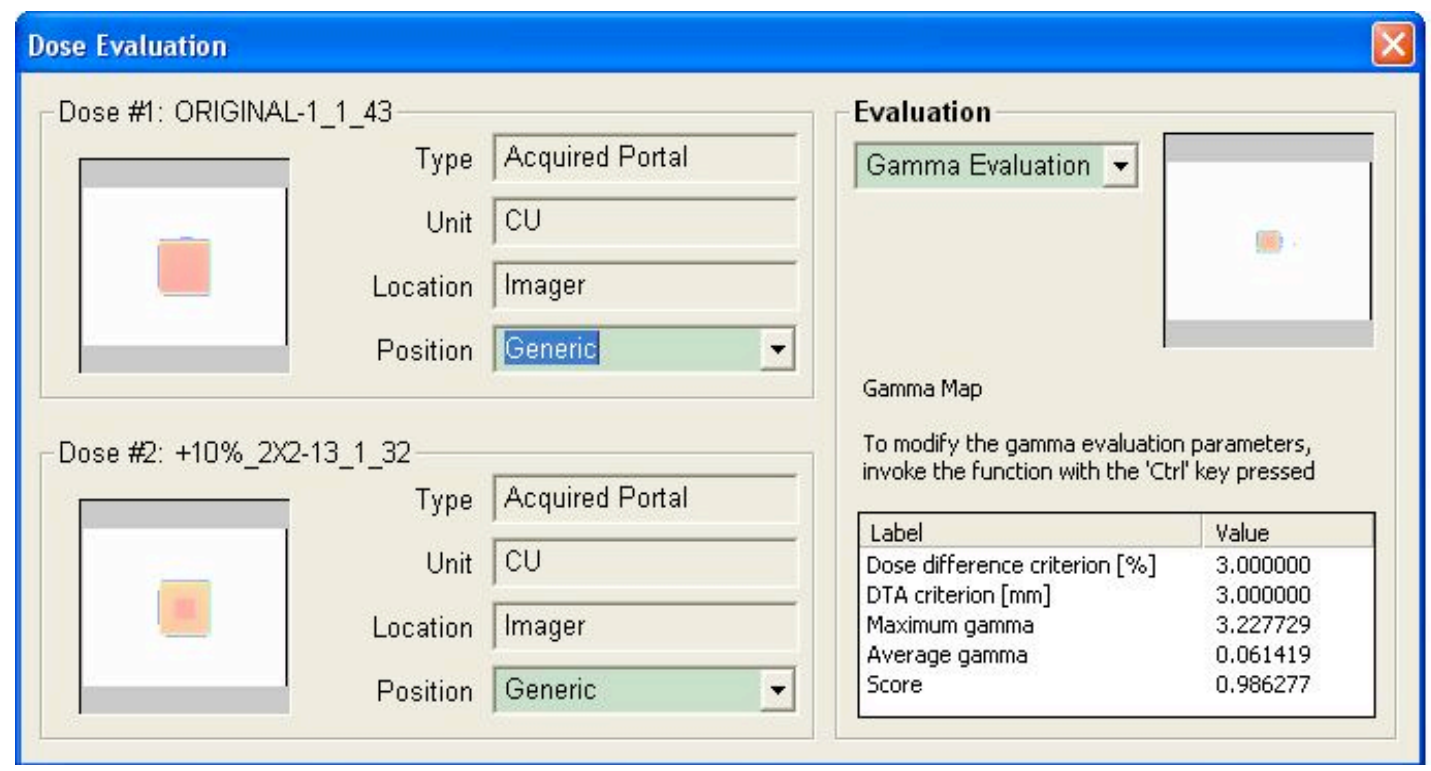

Figura 27: Análise gama das fluências - (a) fluência original; (b) fluência com erro de $+10 \%$ em uma área de $4 \times 4 \mathrm{~cm}^{2}$; (c) gráfico da função gama; (d) parâmetros quantitativos da função gama.

Os parâmetros quantitativos da função gama foram apresentados na Tabela 9.

Na figura 28 observa-se o gráfico da função gama no qual os valores de gama são distribuídos em uma escala de cores que segue o mesmo princípio dos gráficos das fluências, ou seja, o valor de gama aumenta do azul para o vermelho. Portanto, pode-se notar a presença de uma região com valores gama mais altos 
(acima de 1,00) exatamente na região onde foi introduzido o erro (área de $4 \times 4 \mathrm{~cm}^{2}$ a partir do raio central). Por essa razão pode-se afirmar que a análise do gráfico da função gama é eficiente na detecção de erros das fluências medidas.

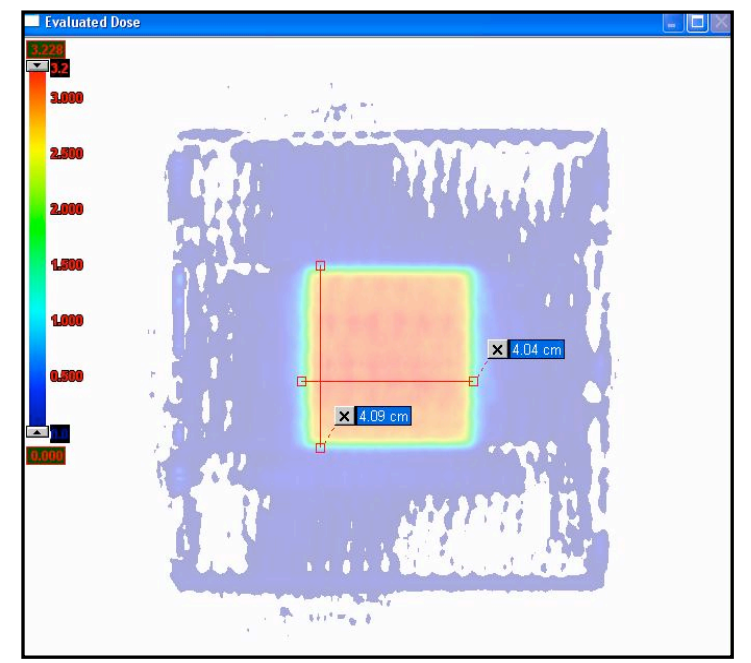

Figura 28: Gráfico da função gama mostrando a área com valores de gama maiores do que 1,00 .

As fluências também foram analisadas através dos perfis de dose obtidos no raio central de cada uma delas. Esses perfis foram obtidos no Eclipse, exportados em arquivos ASCII para o Excel e transformados em gráficos que são apresentados na Figura 29.

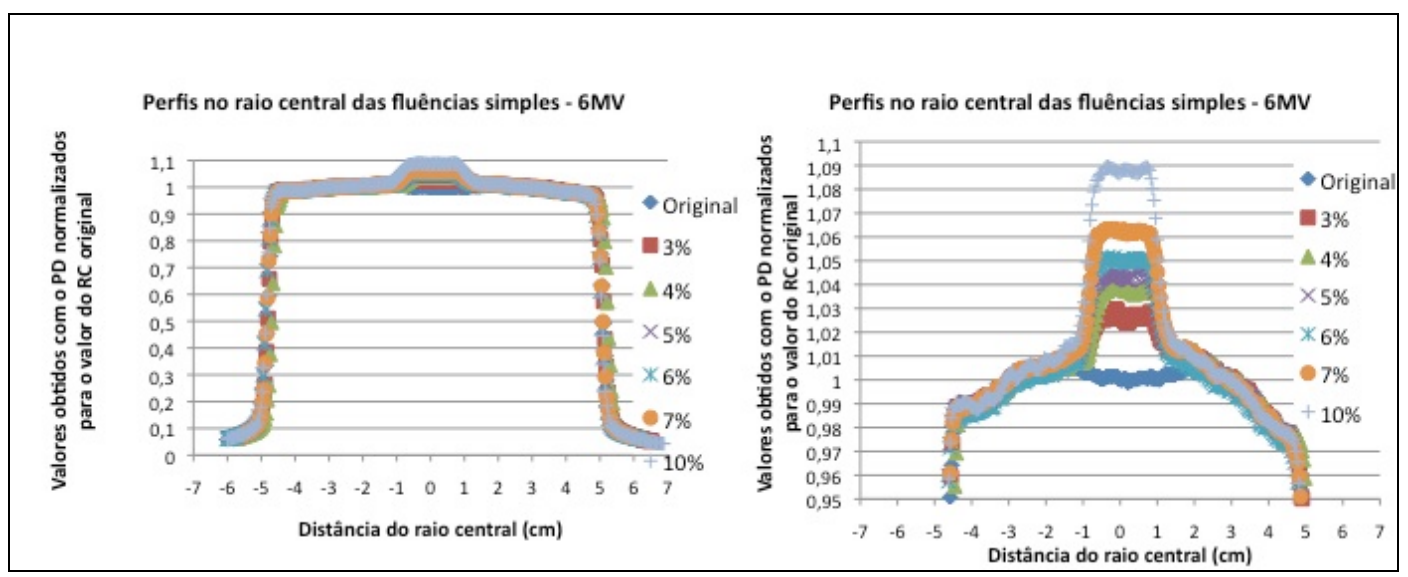

Figura 29: Gráfico dos perfis obtidos no raio central com o portal dosimetry, para os erros introduzidos em uma área de $2 \times 2 \mathrm{~cm}^{2}$. À esquerda os perfis completos e à direita, o mesmo gráfico com escala diferente para dar ênfase às diferenças. 
Pode-se observar na Figura 30 que a comparação visual das fluências medida e esperada, obtidas com o seven29, já é suficiente para que se note a variação introduzida. $O$ gráfico da função gama e os perfis indicam de uma maneira mais evidente o local e a magnitude da variação.

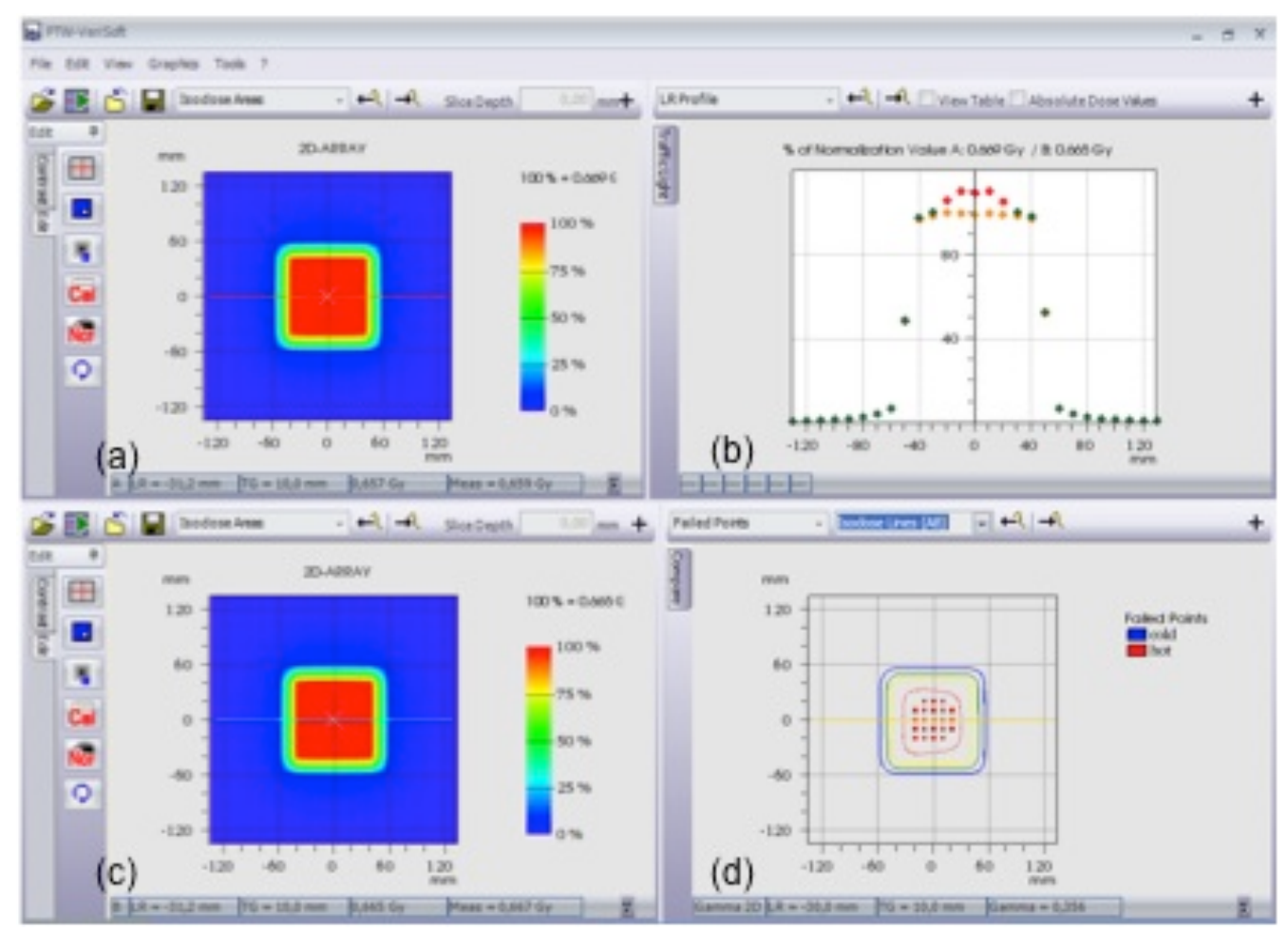

Figura 30: Comparação das fluências obtidas com o seven29.

Também foram introduzidos erros de -3, -5 e - $7 \%$ em campos fora do centro do campo para verificar a possibilidade de detecção de erros em diferentes áreas do campo de tratamento. Na Figura 31 pode-se observar a comparação das fluências esperada e medida para erros introduzidos fora da região do raio central. 


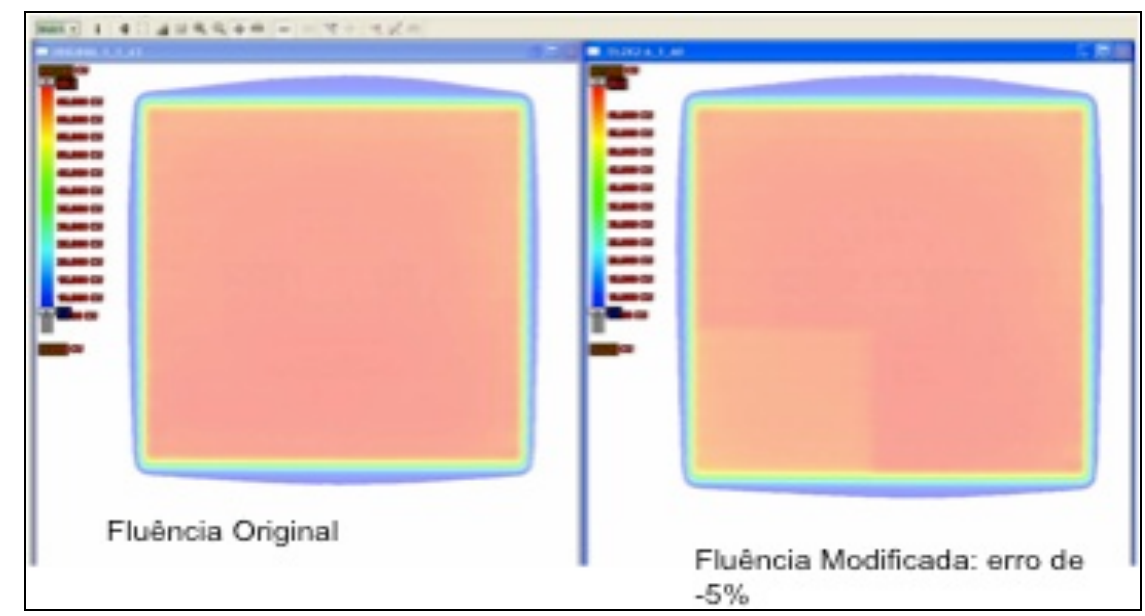

Figura 31: Fluências obtidas com o portal dosimetry - original e com erro de $-5 \%$ em uma área de $4 \times 4 \mathrm{~cm}^{2}$ no limite inferior esquerdo.

Como pode ser notado na Figura acima, as variações de dose introduzidas propositadamente na periferia do campo são facilmente visualizadas.

Na Figura 32 tem-se a análise gama das fluências obtidas com o portal dosimetry.

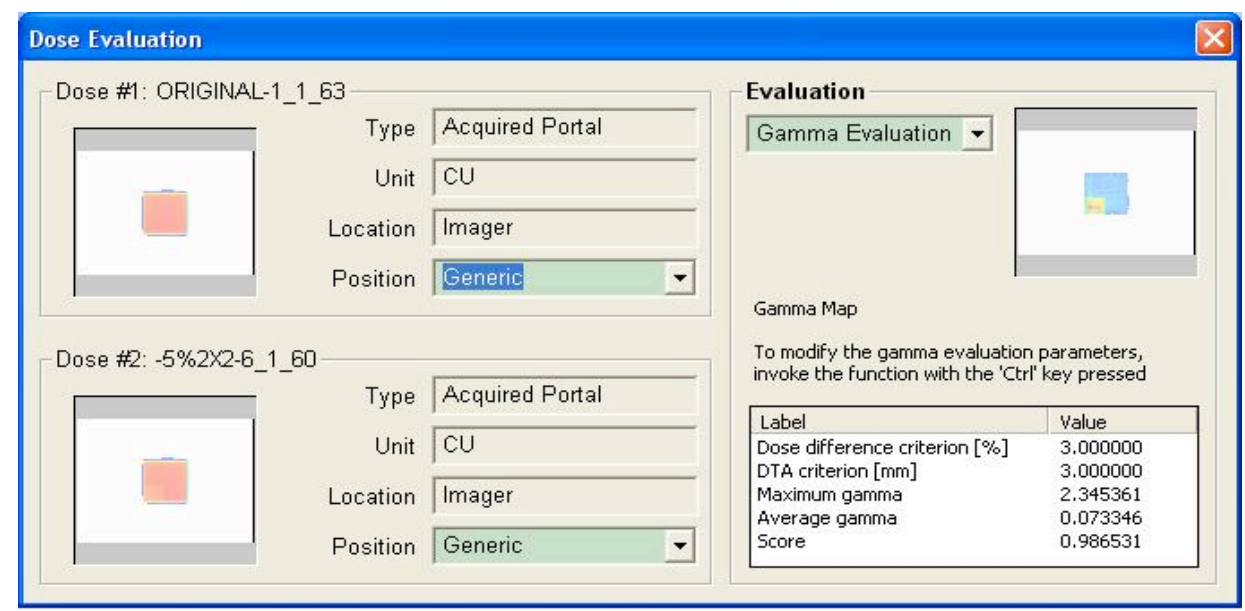

Figura 32: Aplicação da função gama na comparação da fluência original com a fluência na qual foi introduzido um erro de $-5 \%$ em uma área de $4 \times 4 \mathrm{~cm}^{2}$ no limite inferior esquerdo do campo.

A análise do gráfico da função gama indica que o dispositivo portal foi capaz de identificar a presença de uma área com dose diferente da fluência original, ilustrado na Figura 33. 


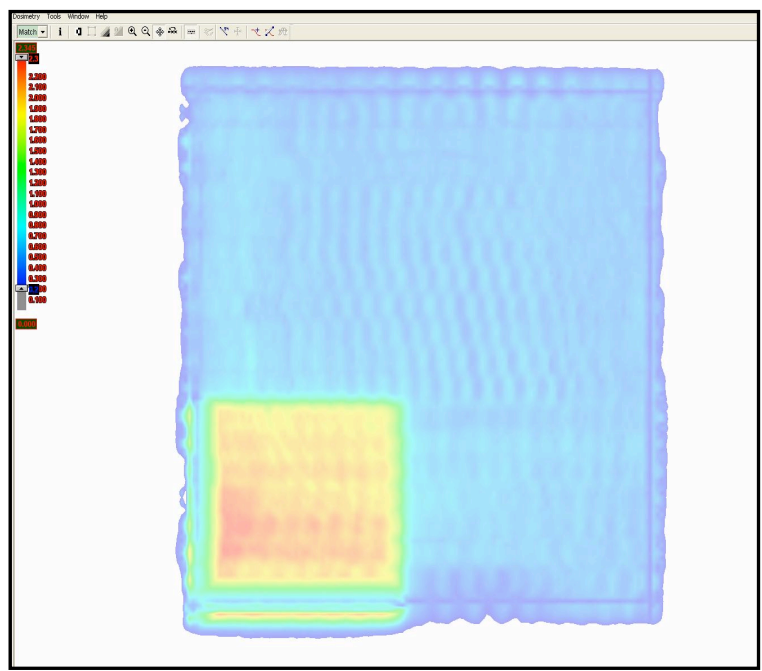

Figura 33: Gráfico da função gama na comparação da fluência original com a fluência na qual foi introduzido um erro de $-5 \%$ em uma área de $4 \times 4 \mathrm{~cm}^{2}$ no limite inferior esquerdo do campo.

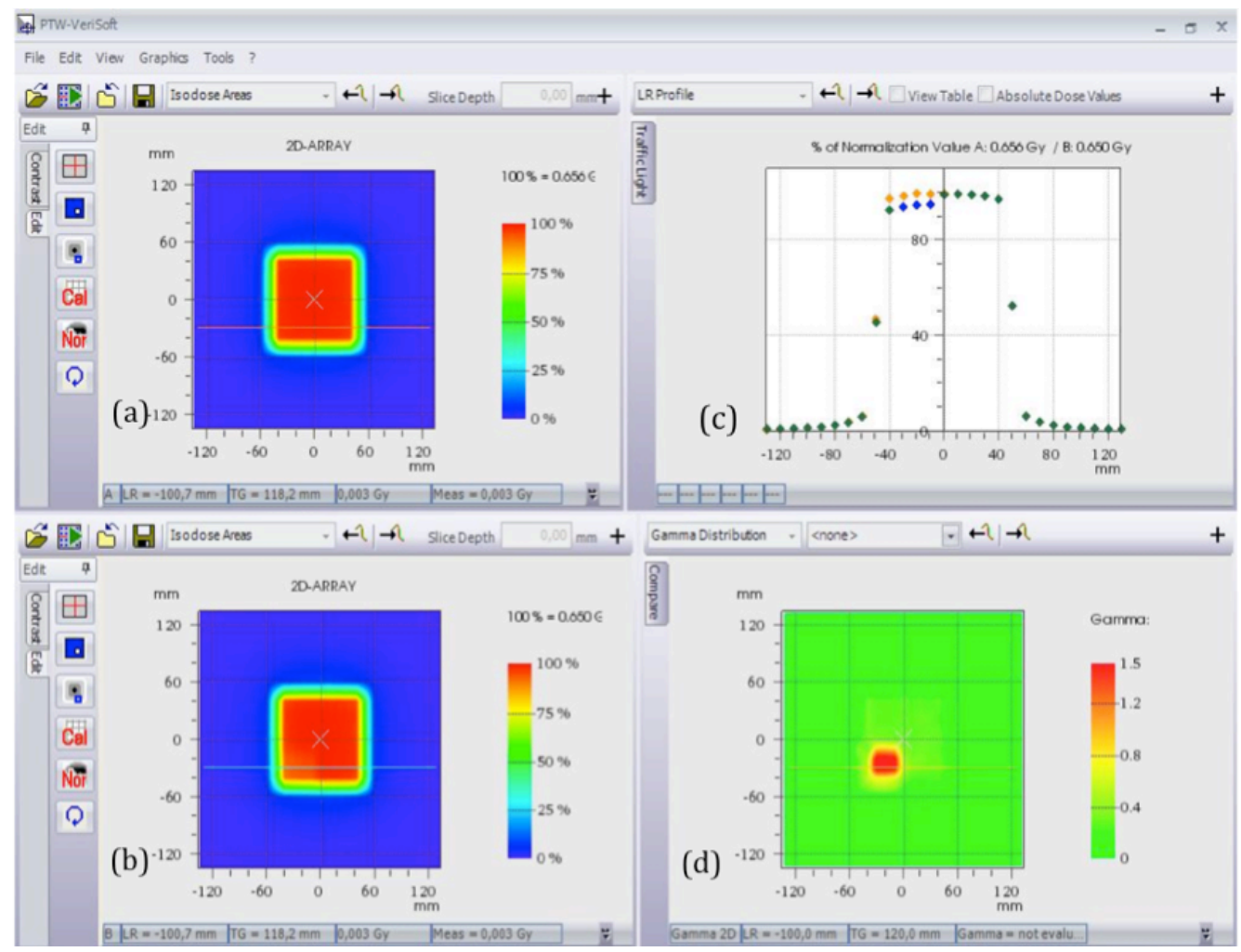

Figura 34: (a) fluência original, (b) fluência com erro de $-5 \%$ na região fora do raio central, (c) gráfico de área da função gama e (d) perfis de dose obtidos com o seven29. 
As medidas das fluências nas quais os erros foram introduzidos em uma região fora do raio central foram feitas com o dispositivo portal e com a matriz de $\mathrm{Cl}$ (seven29). Os dados obtidos com o seven29 para o mesmo erro apresentado nas Figuras 31 e 32 são ilustrados na Figura 34.

Foram analisados também os perfis de dose obtidos na região na qual o erro foi introduzido para o portal dosimetry e o gráfico é apresentado na figura 35.

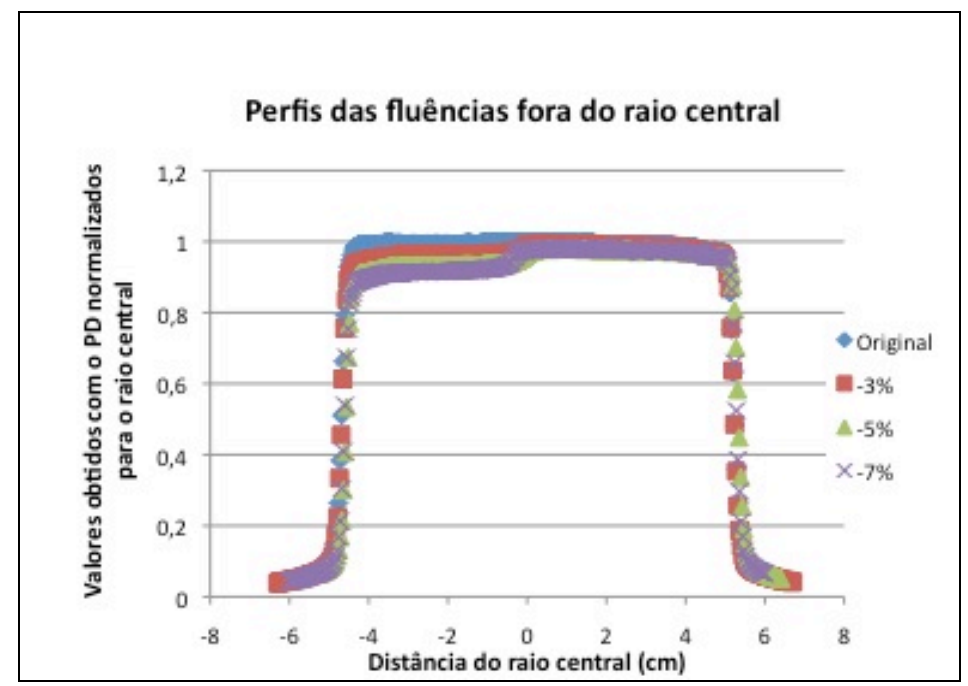

Figura 35: Comparação dos perfis obtidos fora do raio central para o portal dosimetry.

\subsubsection{Avaliação das fluências complexas}

Os valores obtidos das fluências complexas medidos com o portal dosimetry são apresentados na Tabela 11. Foram utilizadas fluências complexas extraídas de um planejamento de próstata com intensidade modulada do feixe. As medidas no raio central são apresentadas para a fluência original e para as fluências modificadas e as diferenças entre elas correspondem aos erros introduzidos propositalmente: campos 1 e $2=+10 \%$, campo $3=-10 \%$, campo $4=$ $-3 \%$ e campo $5=-7 \%$, como pode ser observado no gráfico da figura 37 . 
Tabela 11: Valores de dose no raio central, gama máximo e índice gama obtidos com o portal dosimetry para as fluências complexas medidas.

\begin{tabular}{|c|c|c|c|c|c|}
\hline Campo & $\begin{array}{c}\text { Original } \\
\text { Medida (U.C.) }\end{array}$ & $\begin{array}{l}\text { Modificadas } \\
\text { Medida (U.C.) }\end{array}$ & $\begin{array}{c}\text { Erros } \\
\text { introduzidos }\end{array}$ & $\begin{array}{l}\text { Gama } \\
\text { máximo }\end{array}$ & $\begin{array}{l}\text { Índice } \\
\text { gama }\end{array}$ \\
\hline 1 & $\begin{array}{c}52,975 \pm \\
0,002\end{array}$ & $58,002 \pm 0,062$ & $+10 \%$ & 2,68 & 0,978 \\
\hline 2 & $\begin{array}{c}47,204 \pm \\
0,004\end{array}$ & $51,636 \pm 0,068$ & $+10 \%$ & 2,54 & 0,978 \\
\hline 3 & $\begin{array}{c}49,247 \pm \\
0,006\end{array}$ & $44,238 \pm 0,070$ & $-10 \%$ & 2,81 & 0,995 \\
\hline 4 & $\begin{array}{c}50,914 \pm \\
0,011\end{array}$ & $49,857 \pm 0,075$ & $-3 \%$ & 1,13 & 0,999 \\
\hline 5 & $\begin{array}{c}43,354 \pm \\
0,017 \\
\end{array}$ & $40,272 \pm 0,078$ & $-7 \%$ & 3,59 & 0,984 \\
\hline
\end{tabular}

Os valores de índice gama não apresentam uma definição no comportamento em função do erro introduzido, como pode ser melhor observado no gráfico da Figura 36, que ilustra o valor do índice gama em função do campo. Pode-se notar que o campo 4 , no qual foi introduzido um erro de $-3 \%$, apresenta um índice gama menor que os campos 1 e 2 , nos quais foram introduzidos erros de $+10 \%$.

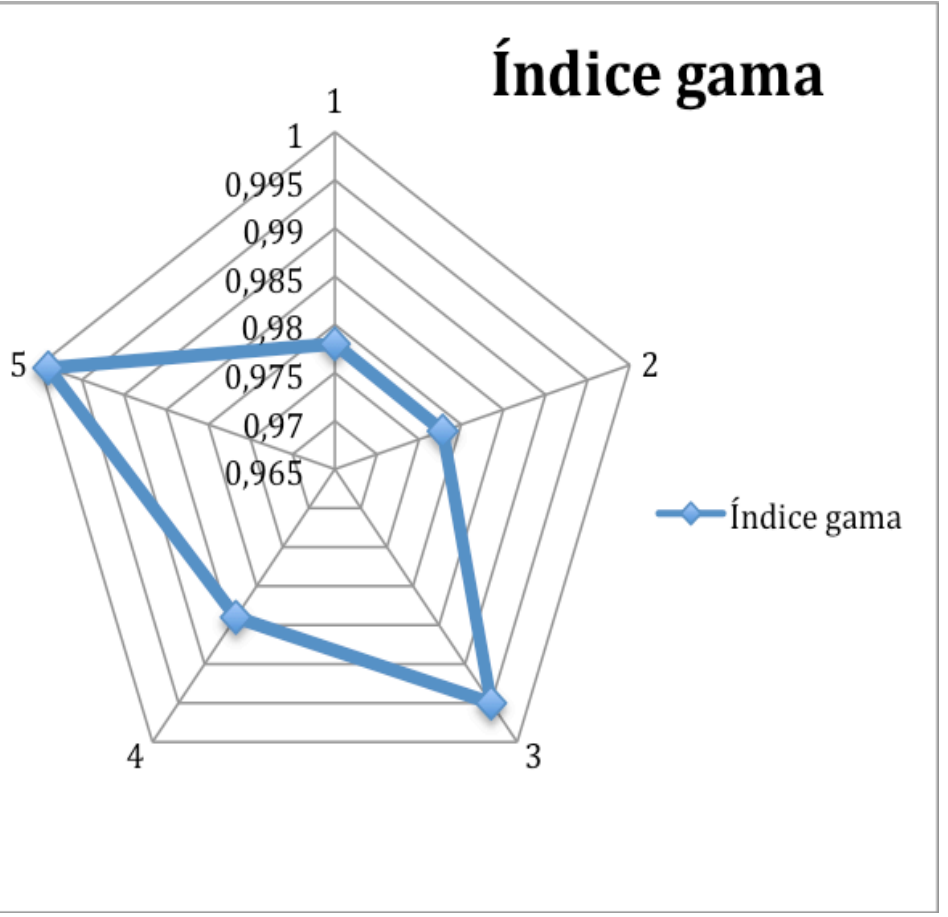

Figura 36: Gráfico ilustrativo do comportamento do índice gama em função do campo. 
A Figura 37 ilustra a comparação dos valores obtidos com a $\mathrm{Cl}$, o seven29 e o PD para cada campo de fluência complexa e pode-se observar que o dosímetro portal apresenta novamente, assim como nas fluências simples, uma resposta equivalente aos outros sistemas dosimétricos.

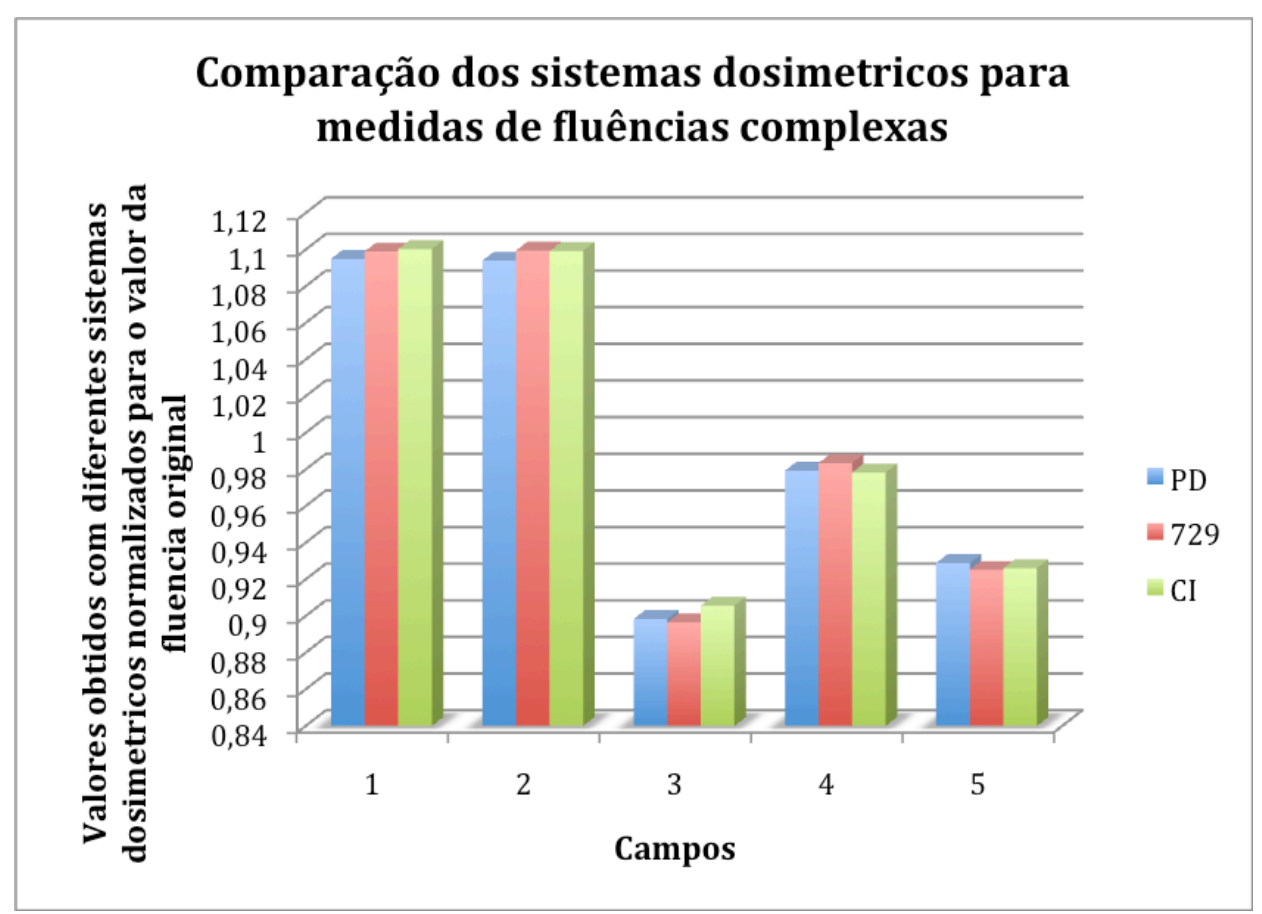

Figura 37: Gráfico dos valores de dose, de cada campo, medidos no raio central com a câmara de ionização, com o seven29 e com o portal dosimetry, normalizados para os valores obtidos da fluência original.

Na Figura 38 observa-se que os erros introduzidos nas fluências são facilmente identificados visualmente, sendo que quanto maior é a área de erro mais fácil é a identificação. Também pode-se afirmar que erros positivos, ou seja, dose em excesso, são mais facilmente identificados sem alterar a escala de unidade de medida. Porém, todos os erros são identificados de maneira mais enfática ao se alterar a escala de dose presente em cada fluência. 


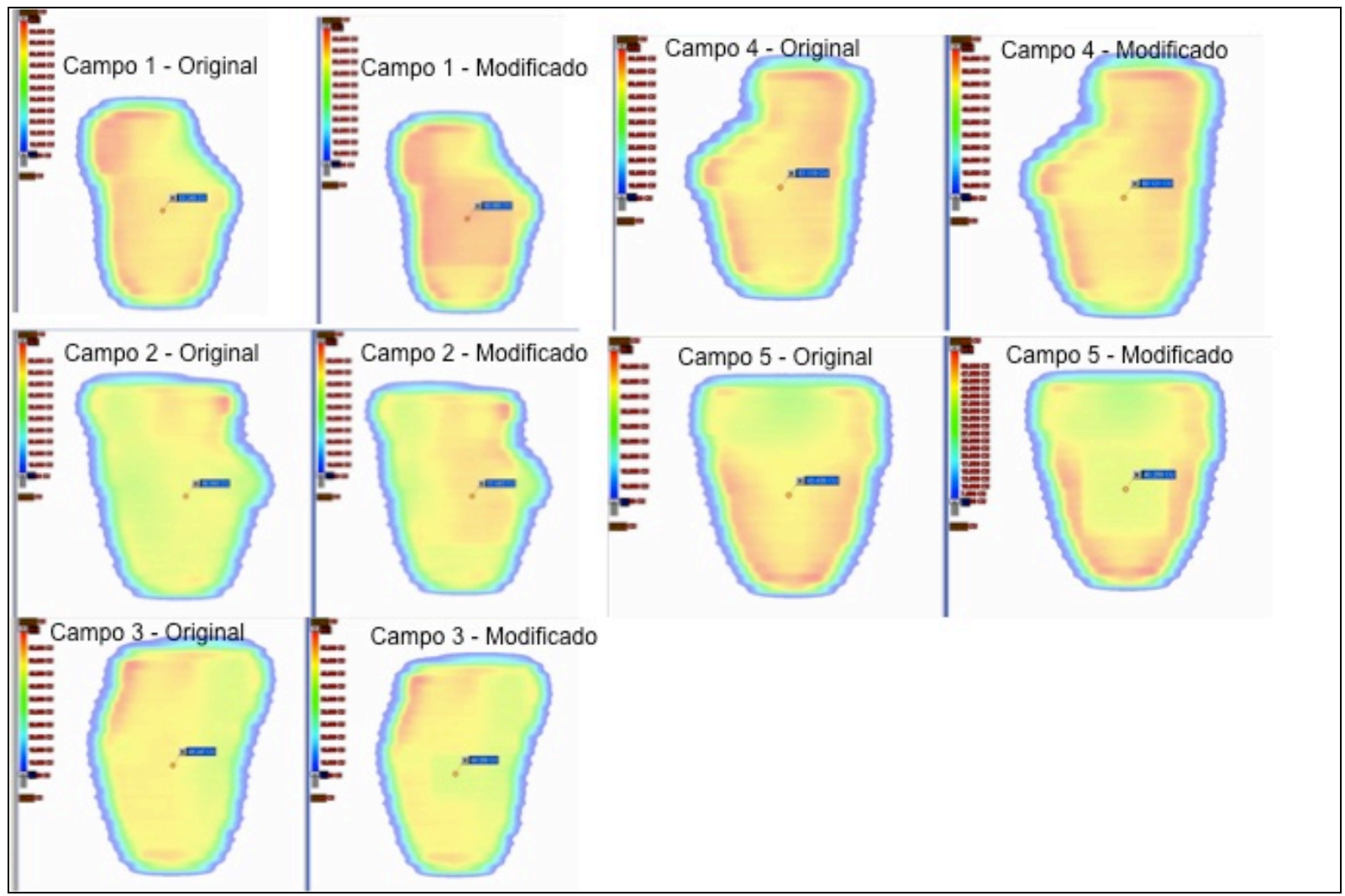

Figura 38: Fluências complexas, originais e modificadas, obtidas com o dispositivo portal.

Analisou-se, também, os perfis dos cinco campos avaliados através da comparação entre os dados obtidos no raio central da fluência original e da fluência modificada. Esses perfis são ilustrados nos gráficos da Figura 39. Esses perfis foram obtidos utilizando-se ferramentas do próprio software de análise do dosímetro portal e em seguida eles foram exportados para o Excel para poder ser realizada a comparação das curvas. 


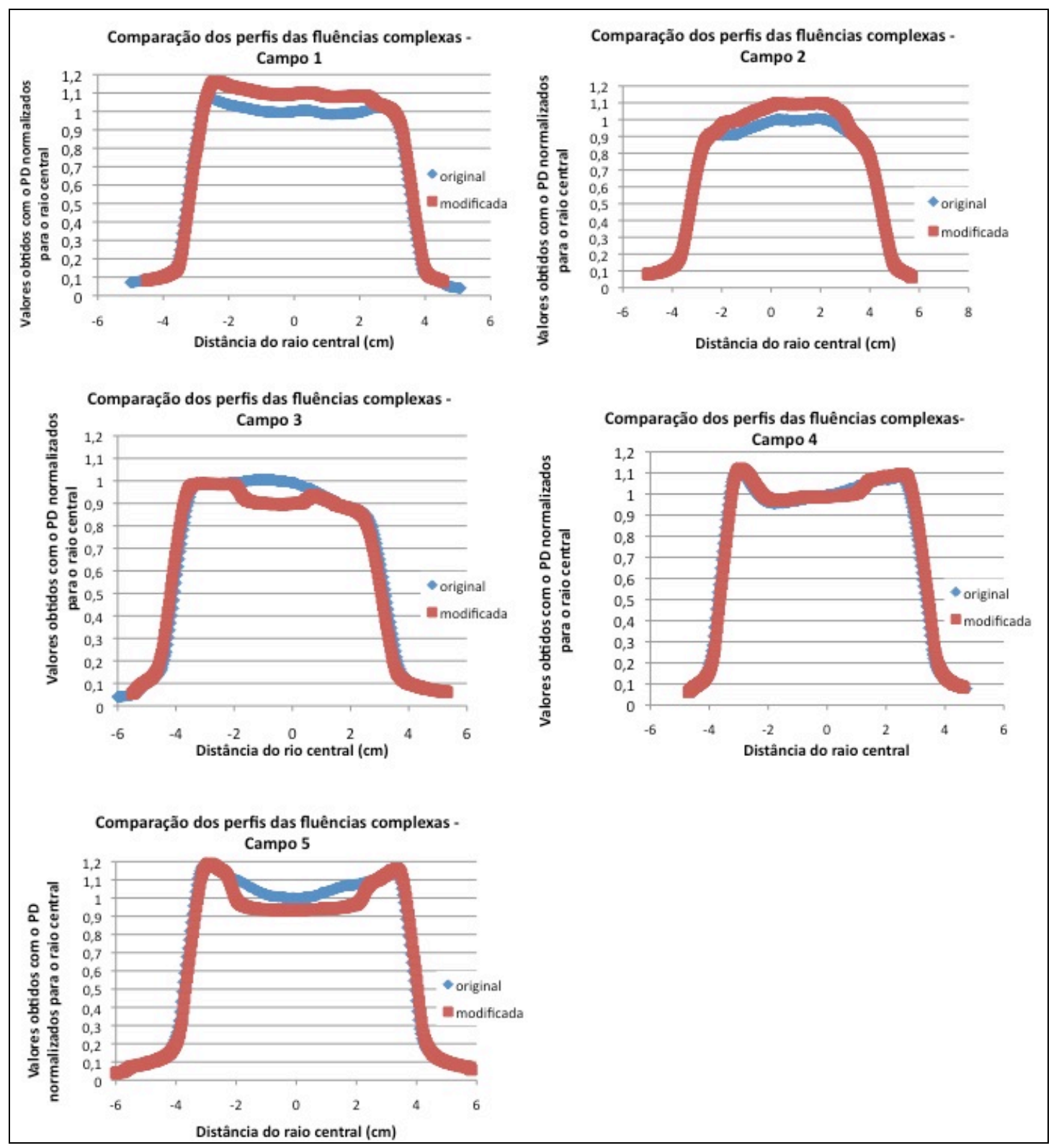

Figura 39: Ilustração dos gráficos dos perfis das fluências complexas obtidos com o PD normalizados para o raio central (original). 


\section{CONCLUSÕES}

Os testes de comissionamento indicam que o dispositivo portal pode ser utilizado para realizar medidas de dose em controles de qualidade em radioterapia, pois apresenta comportamento adequado para esse fim. Esse comportamento inclui os seguintes parâmetros: a linearidade da resposta com a dose; a independência da resposta com a taxa de dose; a uniformidade da resposta em toda a área ativa do dispositivo; a reprodutibilidade das respostas; a independência direcional das respostas em relação ao cabeçote e a subordinação das respostas à lei do inverso do quadrado da distância, ou seja, todas as características desejáveis para um dosímetro em radioterapia.

A análise da capacidade do portal dosimetry em detectar diferenças de dose nas fluências medidas demonstrou a habilidade desse dispositivo na análise dos controles de qualidade de fluências simples, já que o mesmo apresentou resultados que diferiram em menos de $1 \%$ com os outros sistemas de dosimetria já consagrados como a câmara de ionizaçao, o seven29 e o filme. Os dados indicam que é possível detectar erros de diversas magnitudes, porém é necessária uma análise quantitativa e qualitativa das fluências. Isso ocorre porque nem o índice gama, nem o valor de gama máximo, podem assegurar que o controle de qualidade é satisfatório já que o valor de gama máximo não é representativo por se tratar de pontos isolados e o valor do índice gama pode ocultar a presença de áreas com erros significativos pelo fato de ser aplicado em toda a área ativa do dispositivo, independente do tamanho do campo em questão. O resultado do controle de qualidade só deve ser definido após a avaliação qualitativa das fluências, ou seja, da comparação visual das fluências medida e esperada, da avaliação visual do gráfico da função gama e dos gráficos dos perfis comparativos das fluências.

Os conceitos obtidos das análises dos controles de qualidade das fluências simples foram aplicados na avaliação das fluências complexas e os mesmos resultados foram observados, ou seja, é possível utilizar o portal dosimetry para 
realizar o controle de qualidade de fluências moduladas desde que seja feita uma análise não só quantitativa mas também qualitativa das fluências. Esses resultados são fundamentais para concluir que o dispositivo portal é equivalente aos outros métodos de medida já consagrados pois as fluências complexas, utilizadas clinicamente, possuem altos gradientes de dose e por essa razão diferenças de dose indesejadas causadas por falhas na entrega da dose se tornam menos perceptíves em relação às fluências simples. 


\section{Referências}

1. SALVAJOLLI, J.V.; SOUHAMI, L.; FARIA, S.L. Radioterapia em oncologia. 1a. ed. MEDSi, 1999.

2. PALTA, J.R.; MACKIE, T.R.; CHEN, Z. Intensity Modulated Radiation Therapy - The State of the Art. Med. Phys. Vol 30, pp. 3265, 2003.

3. SPIROU, S.V.; CHUI, C.S. A gradient inverse planning algorithm with dosevolume constraints. Med. Phys., vol 25, pp. 321-333, 1998.

4. BOYER, A.L.; BORTFELD, T.; KAHLER, D.L.; STARKSHALL, G.; WALDRON, T. Realization and verification of three-dimensional conformal radiotherapy with modulated fields. Int J Radiat Oncol Biol Phys, vol 30, pp. 889-908, 1994.

5. AGAZARYAN, N.; SOLBERG, T.D.; DEMARCO, J.J. Patient specific quality assurance for the delivery of intensity modulated radiotherapy. J. Appl. Clin. Med. Phys., vol 4, pp. 40-50, 2003.

6. DONG, L.; ANTOLAK, J.; SALEHPOUR, M.; FORSTER, K.; O’NEILL, L.; KENDALL, R.; ROSEN, I. Patient-specific point dose measurement for IMRT monitor unit verification. Int. J. Radiat. Oncol. Biol. Phys., vol. 56, pp. 867-877, 2000.

7. LE'TOURNEAU, D.; GULAM, M.; YAN, D.; OLDHAM, M.; WONG, J. W. Evaluation of a 2D diode array for IMRT quality assurance. Radiother. Oncol, 2004.

8. GREER, P. B.; VIAL, P.; OLIVER, L.; BALDOCK, C. Experimental investigation of the response of an amorphous silicon EPID to intensity modulated radiotherapy beams. Med. Phys., vol. 34, pp. 4389-4398, 2007.

9. LANGMACK K A. Review article: Portal imaging, Brit. J. Rad., vol. 74, pp. 789-804, 2001.

10. HEINTZ, B.; HAMMOND, D.; CAVANAUGH, D.; ROSENCRANZ, D. A Comparison of MatriXX, MapCHECK and Film for IMRT QA: Limitations of 2D Electronic Systems. Med. Phys., vol. 33, pp. 2052-2053, 2006.

11.POPPE, B.; BLECHSCHMIDT, A.; DJOUGUELA, A.; KOLLHOFF, R.; RUBACH, A.; WILBORN, K.C.; HARDER, D. Two-dimensional ionization 
chamber arrays for IMRT plan verification. Med. Phys., vol. 33, pp. 10051015, 2006.

12.ZIJTVELD, M.; DIRKX, M.L.P.; BOER, H.C.J.; HEIJMEN, B.J.M. 3D dose reconstruction for clinical evaluation of IMRT pretreatment verification with an EPID. Radiother. Oncol., vol. 82, pp. 201-207, 2007.

13.STECIW, S.; WARKENTIN, B.; RATHEE, S. Three-dimensional IMRT verification with a flat-panel EPID. Med. Phys., vol. 32, pp.600-612, 2005.

14. ESCH, A.V., The use of an aSi-based EPID for routine absolute dosimetric pre-treatment verification of dynamic IMRT fields. Radiother. Onco.I, vol. 71, pp.223-234 A, 2004.

15. LOW, D.A.; DEMPSEY, S.M.J.F.; GERBER, R.L.; BOSCH, W.R.; PEREZ, C. A.; PURDY, J.A. Quantitative dosimetric verification of a IMRT planning and delivery system. Radiother. Oncol., vol. 49, pp. 305-316, 1998.

16.XING, L.; LI, J.G. Computer verification of fluence map for intensity modulated radiation therapy. Med. Phys., vol. 27, pp.2084-2092, 2000.

17. ROSEN, C.I. The design and testing of novel clinical parameters for dose comparison. Int J Radiat Oncol Biol Phys, 56: 1464-1479, 2000.

18. MORAN, J.M.; RADAWSKI, J.; FRAASS, B.A. A dose-gradient analysis tool for IMRT QA. J Appl Clin Med Phys, 2005.

19. SPEZI, E.; LEWIS, D. Gamma histograms for radiotherapy plan evaluation. Radiother. Oncol., vol. 79, pp. 224-230, 2005.

20.MUNDT, A.J.; ROESKE, J.C. Intensity modulated radiation therapy: a clinical perspective. Hardcover, 2005.

21.PURDY, J.A.; PALTA, J.R.; BOYER, A.L; LOW, D.A. Intensity-modulated radiotherapy: current status and issues of interest. Int. J. Radiation Oncology Biol. Phys., Vol 51 (4), pp. 880-910, 2001

22. CHOI, B.; DEASY, J. The generalized equivalent uniform dose function as a basis for intensity-modulated tratment planning. Phys. Med. Biol, Vol. 47 (20), pp. 3579-3589, 2002.

23. SANTIAGO, R.J.; GLASTSTEIN, E. Pros and cons of IMRT.

24. INTERNATIONAL ATOMIC ENERGY AGENCY, Specification and acceptance testing of radiotherapy treatment planning systems - TECDOC 1540, IAEA, Vienna, 2007. 
25. INTERNATIONAL ATOMIC ENERGY AGENCY, Commissioning of radiotherapytratment planning systems: testing for typical external beam ttreatment techniques - TECDOC 1583, IAEA, Vienna, 2008.

26. INTERNATIONAL ATOMIC ENERGY AGENCY, Comissioning and quality assurance of computerized planning systems for radiation tratment of câncer - TRS430, IAEA, Vienna, 2004.

27. FRAASS, B.; HUNT, M.; KUTCHER, G.; STARKSCHALL, G. STERN, R.; DYKE, J.V. Quality assurance for clinical radiotherapy treatment planning. Med. Phys. Vol. 25 (10), 1998. (AAPM - Task Group 53).

28. LOW, D.A.; HARMS, W.B.; MUTIC, S.; PURDY, J. A. A techinique for the quantitative evaluation of dose distributions. Med. Phys., vol. 25 (5), pp. 656-661, 1998.

29. VAN DYK, J.; BARNETT, R. B.; CYGLER, J. E.; SHRAGGE, P.C. Comissioning and quality assurance of treatment planning computers. Int. J. Radiat. Oncol. Biol. Phys. Vol. 26, pp.261-273, 1993.

30. VARIAN MEDICAL SYSTEM. Reference guide for portal dosimetry, 2005.

31. WINKLER, P.; HEFNER, A.; GEORG, D. Dose-response characteristics of a amorphous silicon EPID. Med. Phys., vol. 32, pp. 3095 - 3105, 2005.

32. GREER, P.B.; VIAL, P.; OLIVER, L.; BALDOCK, C. Experimental investigation of the response of an amorphous silicon EPID to intensity modulated radiotherapy beams. Med. Phys. Vol. 34, pp.4389-4398, 2007.

33. ROSENFELD, A.B. Electronic dosimetry in radiation therapy. Radiation Measurements, vol. 41, pp. S134-S135, 2007.

34.POPPE, B.; BLECHSCHMIDT, A.; DJOUGUELA, A.; KOLLHOFF, R.; RUBACH, A.; HARDER, D. Two-dimensional ionization chamber arrays for IMRT plan verification. Med. Phys. , vol. 33, pp.1005-1015, 2006

35. WINKLER, P.; HEFNER, A.; GEORG, D. Implementation and validation of portal dosimetry with an amorphous silicon EPID in the energy range from6 to 25 MV. Phys. Med. Biol., vol. 53, pp. 355-365, 2007.

36. KAVUMA, A.; GLEGG, M.; CURRIE, G.; ELLIOT, A. Assessment of dosimetrical performance in 11 Varian a-Si500 electronic portal imaging devices. Phys. Med. Biol., vol. 53, pp. 6893-6909, 2008.

37. HOWELL, R.M.; SMITH, I.P.N.; JARRIO, C.S. Establishing action levels for EPID-based QA for IMRT. J. Appl. Clin. Med. Phys., vol. 9, pp.16-25,2008. 